\title{
AN ALYTICAL ECONOMIC STUDY OF PRODUCTION OF POTATO CROP IN GHARBIA GOVERNORATE
}

\author{
BADR, O. AHMAD, W. A. FARRAG and \\ NAGLAA EL - SAID AHMED SHABAN
}

\author{
Agric. Econ. Res. Instit- ARC, Dokki, Giza, Egypt
}

(Manuscript received 19 December 2015 )

\begin{abstract}
$\mathrm{T}$ he potato crop is considered one of the important vegetable crops in Egypt, which occupies a prominent place among the green plants in the crop structure of Egypt, the average total cultivated potato crop during the period (2008 - 2012) about 355.58 thousand feddans represent about $5.5 \%$ of the annual average total area cultivated vegetables in Egypt, which is estimated at 6412.3 thousand feddans during the same period, while the average total quantity of production of potatoes about 3.94 million tons represented about $11.9 \%$ of the average annual total production of Egyptian vegetables estimated at about 75.53 million tons in Egypt during the same period. The problem potatoes crop is consendered the most important of food vegetables crops for habitants in Egypt .but the production of this crop represents only $11.9 \%$ from the totalof vegetables production in A .R .E, in addition to the damage proportion in this crop is estimated with about $12 \%$,that leads to reduce unclear in production which that lead to rising the production costs of potato crop. The research aims to study the current situation of production and cost for potato crop on the level of Gharbia Governorate, and studying the productive efficiency of the most important resources used in potato production, Also study the costs of production of this crop. The research results from the variance analysis of moral differences between the micanical labor of feddan used for potato to the first category and the second category in sample of each: irrigation machine, mator spraying, tractor, harvest tractor, for potato crop in the first category, the condition of economic efficiency has been achieved on the level of the total resources as long as there is an increase in the output of the potato crop, but less than the rate of increase in resources, where the relationship of decreasing productivity. Either for each supplier separately, a condition of economic efficiency and increase the value of marginal product of wages prevailing in the market for each component of the seeds, and the element of irrigation, but still possible to increase the efficiency by increasing the elements of production until the equal value of marginal productive of component and with the its price in the market, also the condition of economic efficiency in the second category has been achieved on the level of the total resources, and on the level of each of the element. The research also explained that the optimal size of the farm in the first category of potatoes reached about 11.60 tons, thus, farm size represented about $78.9 \%$ of the optimal size of the farm, as shown in the search that size which maximizes the profit of the farm of potatoes in this category amounted to about 35.27 tons, since the average farm area is about 0.54 feddans, so the
\end{abstract}




\begin{abstract}
average production per feddan of potatoes in this category amounted to about 16.94 tons and the reseach showed that the optimal size of the farm in the second category of potatoes reached about 27.28 tons, thus, farm size represents about $93.95 \%$ of the optimum size of the farm, as shown in the search that size which maximizes the profit of the farm of potatoes in this category About 59.92 tons, since the average farm area is about 1.54 feddans, so the average production per feddan of potatoes in this category amounted to about 16.64 tons.
\end{abstract}

\title{
RECOMMENDATIONS
}

Recommend to cultivate potatoes in areas feddans and more (category II Sample), which will lead to the reduction of production costs and thus improving the efficiency and productivity per ton. 


\title{
دراسة اقتصادية تحليلية لإتاج وتكاليف محصول البطاطس بمحافظة الغربية
}

\author{
عمر أحمد بلر وجيه عبد العزيز فراج نجلاء السيد أحمد شعبان \\ معهز بحوث الاقتصاد الزراعى - مركز البحوث الزر اعبة - دقى - جيزة \\ الملخص
}

يعتبر محصول البطاطس من محاصيل الخضر الرئيسة فى مصر والتى تحنل مكانة بارزة بين الزروع الخضرية فى التزكيب المحصولي فى مصر ، فقد بلغ منوسط إجمالى المساحة

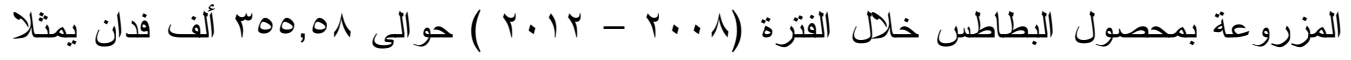
نحو 0,0 \% من المتوسط السنوي لإجمالي مساحة الخضر المزروعة بجمهورية مصر العربية الذى

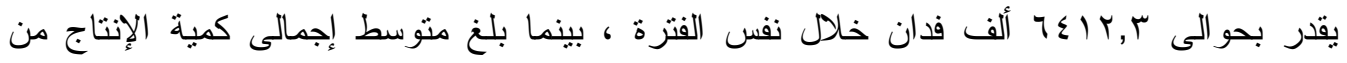

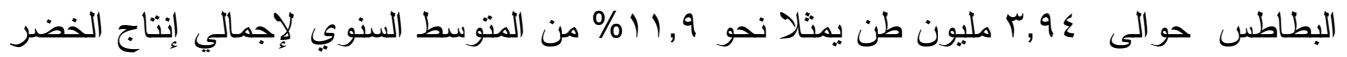

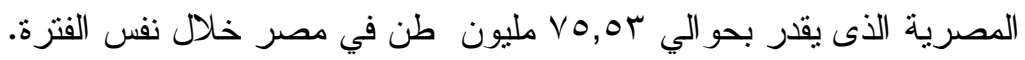

تتمثل مشكلة البحث في ارتفاع التكاليف الإنتاجية لمحصول البطاطس في محافظـــة الغربيـــة

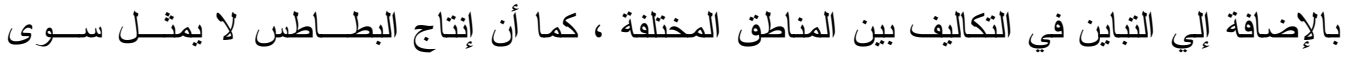

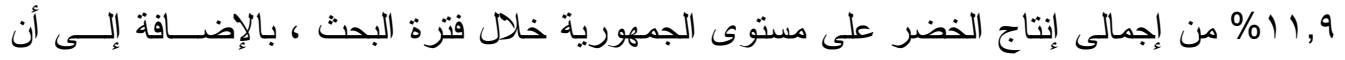

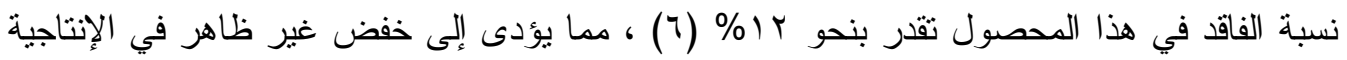
وبالثالي ارتفاع تكاليف إنتاج الوحدة، و انخفاض صافى العائد الفدان •

يهدف البحث إلي دراسة الوضع الإنتاجي الر اهن لمحصول البطاطس على مستوى محافظـــة الغربية ، ودر اسة الكفاءة الإنتاجية لأهم الموارد المستخدمة في إنتـــاج البطــاطس، ودر اســـة دالـــة التكاليف لإنتاج محصول البطاطس وذللك للتعرف علي أهم المشكلات التي تو اجه إنتاج البطاطس في محافظة الغربية وبصفة خاصة ارتفاع التكاليف الإنتاجية للمحصول .

و أوضحت نتائج البحث من تحليل التباين وجود فروق معنوية بين العمل الآلي المستخدم لفدان البطاطس للفئة الأولى والفئة الثانية بالعينة لكل من : ماكينة الري ، موتور الرش، خدمة

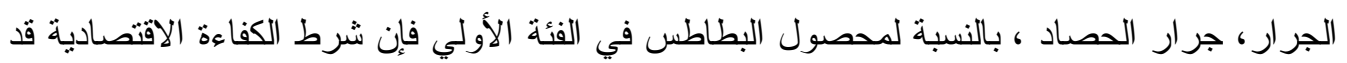
تحقق على مستوى إجمالي الموارد طالما أن هناك زيادة في الناتج من محصول البطاطس، ولكنها أقل من نسبة الزيادة في الموارد، حيث كانت العلاقة الإنتاجية متتاقصة ـ أما بالنسبة لكل مورد على لهـ حده فقد تحقق شرط الكفاءة الاقتصادية وهو زيادة قيمة الناتج الحدي للمورد عن أجره السائد في السوق لكل من عنصر التقاوي، وعنصر الري، ولكن لازال بالإمكان زيادة هذه الكفاءة بزيادة عناصر الإنتاج حتي يتساوي قيمة الناتج الحدي للعنصر مع سعره السائد في السوق ، أيضا فإن شرط الكفاءة الاقتصادية قد تحقق على مستوى إجمالي الموارد طالما أن هناك زيادة في الناتج من محصول البطاطس، ولكنها أكثر من نسبة الزيادة في الموارد ، حيث كانت العلاقة الإنتاجية منز ايدة، 
أما بالنسبة لكل مورد على حدة فقد تحقق شرط الكفاءة الاقتصادية وهو زيادة قيمة الناتج الحدي للمورد عن أجره السائد في السوق لكل من: عنصر الري، السماد الآزوتي، العمل البشري، السماد الفوسفاتي، ولكن لاز ال بالإمكان زيادة هذه الكفاءة بزيادة عناصر الإنتاج حتي يتساوي قيمة الناتج الحدي للعنصر مع سعره السائد في السوق.

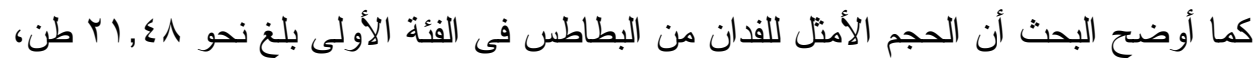

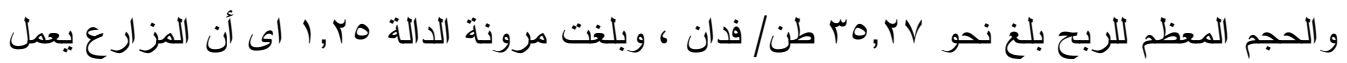

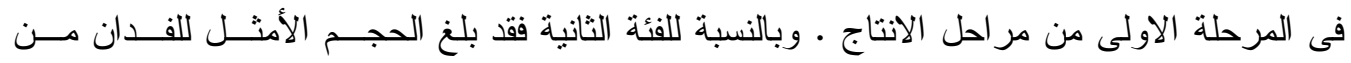

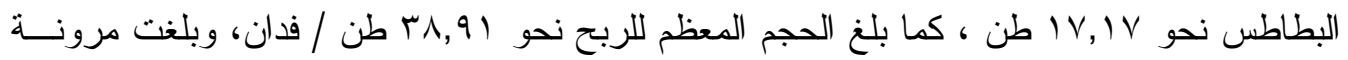
الدالة فى هذه الفئة نحو 797, • ايى أن المزارع يعمل فى المرحلة الاقتصادية وهذا يتفق مع المنطــق

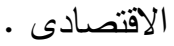

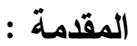

يعتبر محصول البطاطس من محاصيل الخضر الرئيسية فى مصر والتى تحتل مكانة بـارزة

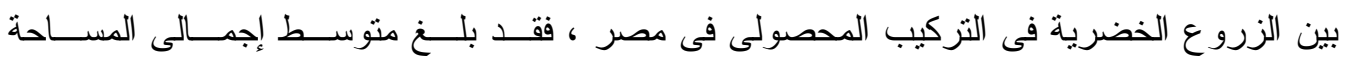

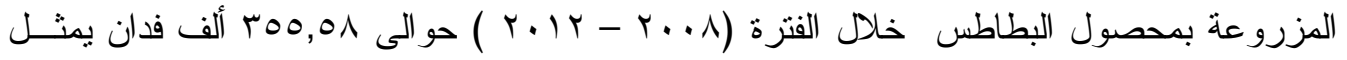
نحو 0,0 \% من المتوسط السنوى لإجمالى مساحة الخضر المزروعة في مصر و الذي يقدر بحـــوالي

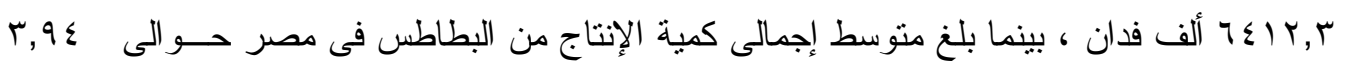
مليون طن يمثل نحو 11 1 \% من المتوسط السنوى لإجمالى إنتاج الخضر المصــرية الـــى يقــدر بحو الى Vo,or مليون طن خلال نفس الفترة .

ويقدر المنوسط السنوى للقيمة النقدية لمحصول البطاطس بالأسعار الجارية فى كل من العروة

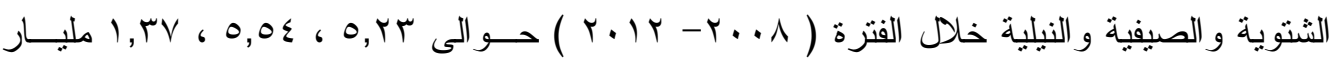

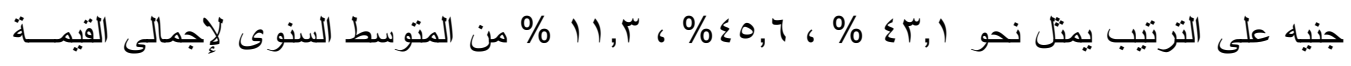

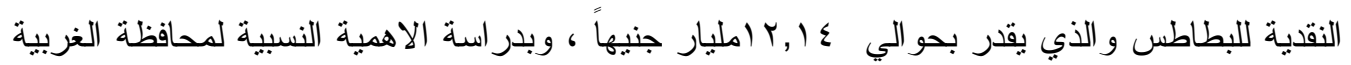

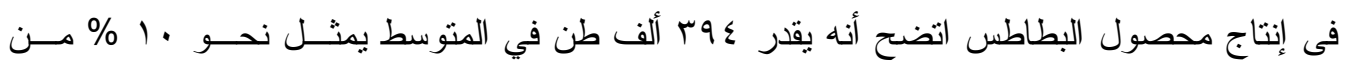
المنتوسط السنوى للكمية المنتجة من البطاطس على مستوى الجمهورية خلال الفترة المشار إليها ـ

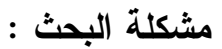

تتمنل مشكلة البحث فى ارتفاع التكاليف الإنتاجية لمحصول البطاطس في محافظـــة الغربيـــة

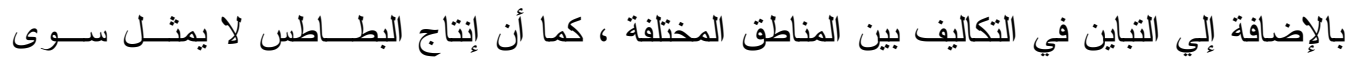

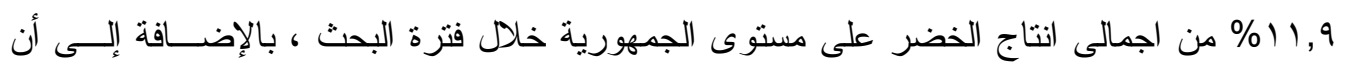

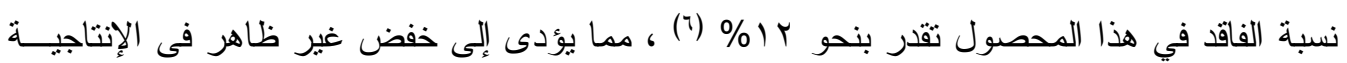
وبالتالي ارتفاع تكاليف انتاج الوحدة، وانخفاض صافى العائد الفدانى . 
يهدف البحث إلي دراسة الوضع الإنتاجي الر اهن لمحصول البطاطس في محافظة الغربية ، ودر اسة الكفاءة الإنتاجية لأهم الموارد المستخدمة في إنتاج البطاطس، ودر اسة دالة التكاليف لإنتــاج محصول البطاطس وذلك للتعرف علي أهم المشكلات التي تو اجه إنتاج البطاطس في محافظة الغربية وبصفة خاصة ارتفاع التكاليف الإنتاجية للمحصول . الأسلوب البحثي ومصادر البيانات :

أعتمد البحث على أسلوبى التحليل الوصفى و الكمى لتقدير وشــرح المتغيـرات الإقتصــادية المتعلقة بالإنتاج و التكاليف والكفاءة الإقتصادية لمحصول البطاطس فى عينة البحث ·حيث نم نطبيق اسلوب الانحدار المتعدد باستخدام طريقة backward، لتقدير اهم العو امـلـل المــؤثرة عـــى انتــاج البطاطس فى الفئتن بعينة البحث . وفيما يتعلق بمصادر البيانات فقد إستتد البحث على نوعين من البيانات : أو لاً البيانات الثانوية

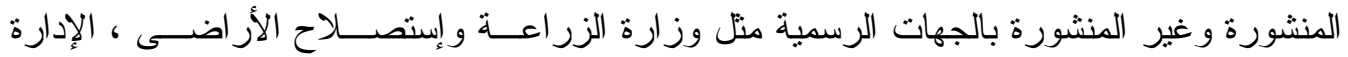

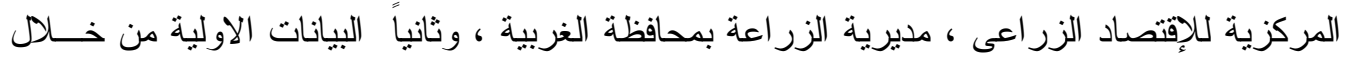
إستمارة إستبيان لعينة ميدانية لزر اع محصول البطاطس بالمر اكز المختارة بعينة البحث بالمحافظة .

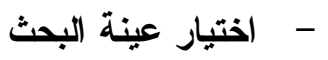

تم اختيار مركزي كفر الزيات و طنطا بمحافظة الغربية وفقاً للاهمية النسبية للمساحة المزروعة بالمركزين ، ونم اختيار كل من قريتي : منشأة سليمان ومشلة بمركز كفر الزيات وقريتي

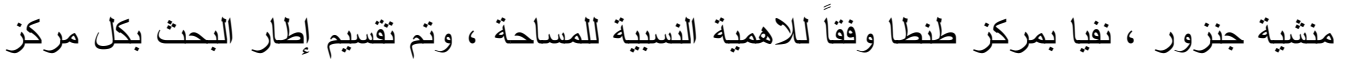

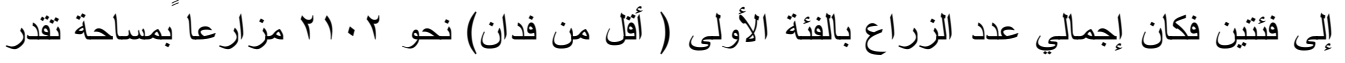

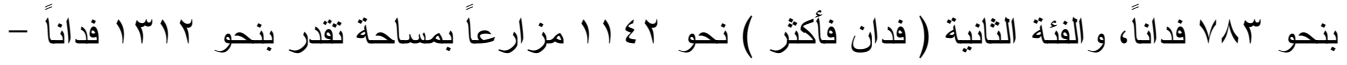

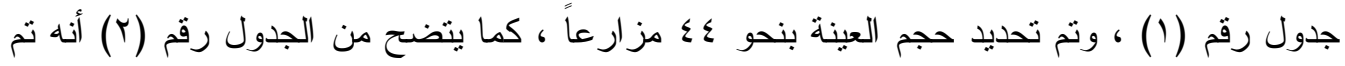

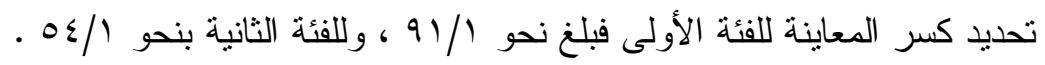

$$
\text { - إطار العينة : }
$$

وتنثير بيانات جدول (ץ) إلي توزيع عينة البحث على قرى العينة فكان نصيب قريتي : منشأة

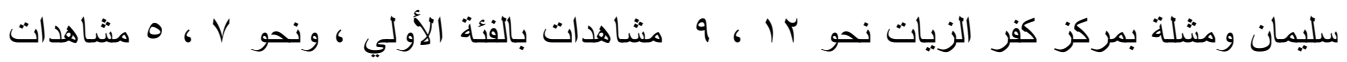

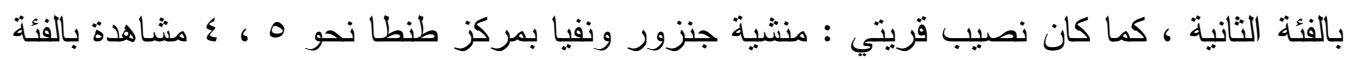

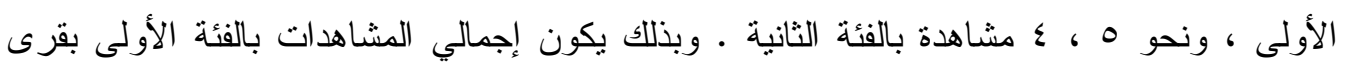

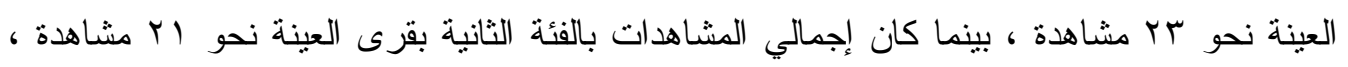
وبذللك يكون إجمالي العينة بالقرى المذكورة في مركزي : كفر الزيات وطنطا نحو ع ؛ مشاهدة . 
جدول رقم ( ) : أعداد مزارعي البطاطس والمساحة المزروعة وفقاً لفئتي البحث بمر اكز وقرى

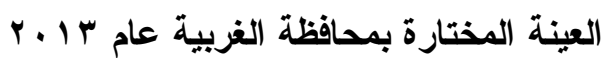

\begin{tabular}{|c|c|c|c|c|c|c|c|c|c|}
\hline \multicolumn{2}{|c|}{ الإجمالي } & \multicolumn{2}{|c|}{ (فلفان فأكثر) } & \multicolumn{2}{|c|}{ (أقل من فدان ) } & \multirow{2}{*}{ القرية } & \multirow{2}{*}{ r } & \multirow{2}{*}{ المركز } & \multirow{2}{*}{ s } \\
\hline (بالفدان) & الزراع عدد & (بالفدان) & الزر اعد & (بالفد ان) & عدد الزراع & & & & \\
\hline VOA & $1, \ldots$ & $\leqslant 7$. & $\varepsilon \ldots$ & rqA & $\wedge \ldots$ & مليمانة & 1 & \multirow{2}{*}{ الزيات } & \multirow[t]{2}{*}{1} \\
\hline$\varepsilon V r$ & vo. & YAV & ro. & 1117 & $0 .$. & مشلة & r & & \\
\hline | & 190. & $V \leqslant V$ & 70. & $\varepsilon \wedge \varepsilon$ & . & \multicolumn{4}{|c|}{ الجملة } \\
\hline sor & 091 & rq. & ror & rד & Th & منزية & r & \multirow[t]{2}{*}{ طنطا } & \multirow[t]{2}{*}{ r } \\
\hline$\leqslant 11$ & $T . r$ & rVo & $r r q$ & ב & Tצ & نفيا & $\varepsilon$ & & \\
\hline 人ฯร & $119 \leq$ & 070 & $\varepsilon q r$ & r99 & $V \cdot r$ & \multicolumn{3}{|c|}{ الجملة } & \\
\hline$r .90$ & $M_{1} \leq \varepsilon$ & & $11 \leqslant r$ & vᄉr & $r \ldots r$ & \multicolumn{3}{|c|}{ الإجمالي العام } & \\
\hline
\end{tabular}

المصدر: مديرية الزر اعة بالغربية ، سجلات إدارة الإحصاء.

جدول رقم (r): تحديد عدد الحائزين المختارين من مزارعي البطاطس وفقا لفئتى عينة البحث

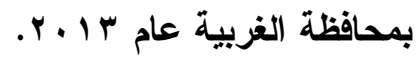

\begin{tabular}{|c|c|c|c|c|c|c|c|c|c|c|}
\hline كسر & العائزين & الهندسي & الهنسي & لنسبة عدائزين × & اللمساحه & 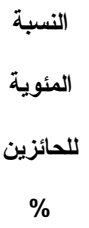 & المنالبزرعة & الحائزين & المركز & p \\
\hline $91 / 1$ & rr & $0 ., 0$ & $\{\wedge, \wedge$ & $r r \Lambda,, T^{\prime}$ & $r v, r v$ & & VAT & $r \ldots r$ & الألفئة & 1 \\
\hline $0 \leqslant / 1$ & r) & $\varepsilon 9,0$ & $\varepsilon v, \uparrow \wedge$ & YTVT, \&V & זד, זד & r ז r & ITIT & $11 \leqslant r$ & الثاتية & $r$ \\
\hline & £ & $1 .$. & $97, \leqslant \wedge$ & $\{70 \leqslant, 1\}$ & $1 \ldots$ & $1 \ldots$ & $r .90$ & rI & الجملة & \\
\hline
\end{tabular}

المصدر : مديرية الزر اعة بالغربية ، سجلات إدارة الإحصاء. 
جدول رقم (ץ): توزيع عينة البحث من مزارعي البطاطس على القرى المختارة وفقا لفئتى العينة

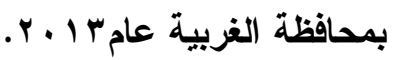

\begin{tabular}{|c|c|c|c|c|c|c|c|}
\hline \multirow[b]{2}{*}{ الإجمالى } & \multicolumn{2}{|c|}{ (فلفئة الثانية } & \multicolumn{2}{|c|}{ (أقل من الأولى) } & \multirow[b]{2}{*}{ القرية } & \multirow[b]{2}{*}{ م } & \multirow[b]{2}{*}{ المركز } \\
\hline & عدد المشاهدات & عدد الزراع & المشتاهدات & عدد الزراع & & & \\
\hline 17 & v & $\varepsilon \cdot \cdot$ & 9 & $\wedge .$. & سنشئأة & (1) & \multirow{2}{*}{ كفر } \\
\hline 1. & o & ro. & - & $0 .$. & مشله & $(\ulcorner)$ & \\
\hline 1. & 0 & ror & - & TrA & جنزئه & $(r)$ & \multirow[t]{2}{*}{ طنطا } \\
\hline$\wedge$ & $\varepsilon$ & rrq & $\varepsilon$ & TIE & نفيا & $(\xi)$ & \\
\hline$\varepsilon \varepsilon$ & r) & $11 \leqslant r$ & rT & $r \cdot \cdot r$ & \multicolumn{3}{|c|}{ الإجمالى العام } \\
\hline
\end{tabular}

المصدر : مديرية الزراعة بالغربية ، سجلات إدارة الإحصاء. النتائج البحثية :

- - التقييم الاقتصادي للفدان من محصول البطاطس : أولاً: تحليل عناصر الإنتاج الفيزيقية للفدان من محصول البطاطس أ- مستلزمات الإنتاج : n

توضح بيانات جدول (ع) وجود اختلافات معنوية في معدلات التقــاوي المســتخدمة لفــــان

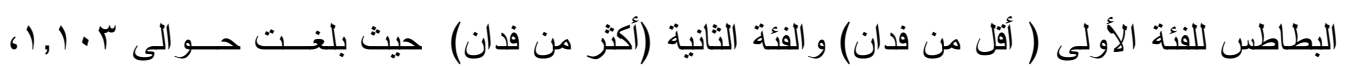

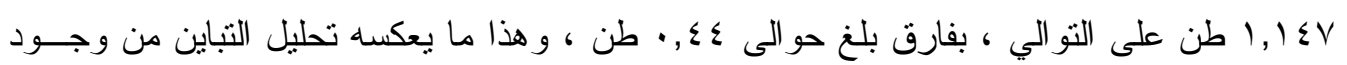

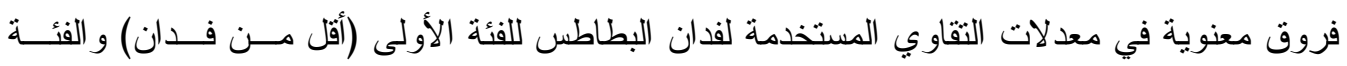

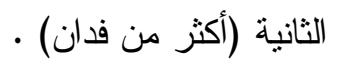

جدول رقم (؛) : المتوسط الفيزيقي للمستلزمات الإتتاجية لفدان البطاطس وفقا

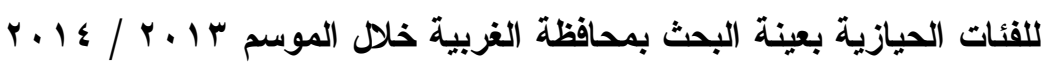

\begin{tabular}{|c|c|c|c|c|}
\hline $\mathbf{F}$ & 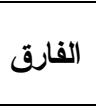 & 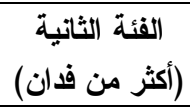 & (أقلّ من فدانة الأولى) & المستلزمات الإتتاجية للفدان \\
\hline$* "(7, r v)$ & $\cdot, \leq \leqslant$ & $1,1 \leq V$ & $1,1 \cdot r$ & التقاوي (بالطن) \\
\hline$r, r r$ & $r, \cdot \Lambda$ & $r v, .0$ & $r q, 1 r$ & السماد بلدي( مץ ) \\
\hline$\cdot, \leqslant 0$ & $r, \leqslant V$ & $\mid v 1,01$ & $1 \vee \varepsilon, .0$ & السماد الأزوتي (بالوحدة) \\
\hline., .9 & 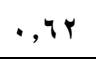 & $v 1,1 \leq$ & $V_{1, V q}$ & السماد الفوسفاتي (بالوحدة) \\
\hline$\because, 1 \mathrm{~V}$ & $1, \cdot 1$ & $\wedge \bullet, \wedge \uparrow$ & $\wedge 7,9 \leq$ & السماد البوتاسي (بالوحدة) \\
\hline "** $(V, r \Delta)$ & $r, \leq 7$ & $r, r v$ & $\checkmark, \wedge r$ & المبيدات (باللتر) \\
\hline
\end{tabular}


وبالنسبة للأسمدة العضوية فيتضح من بيانات نفس الجدول أنه لا توجد اختلافات بين كميـات

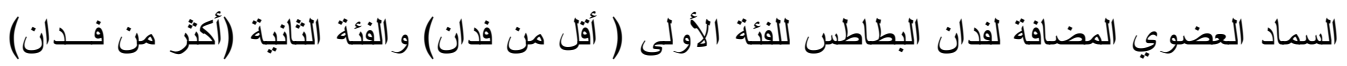

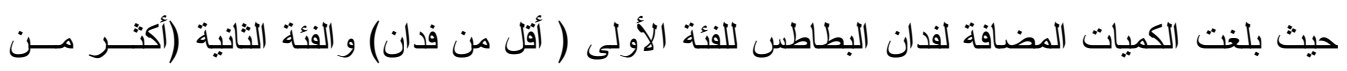

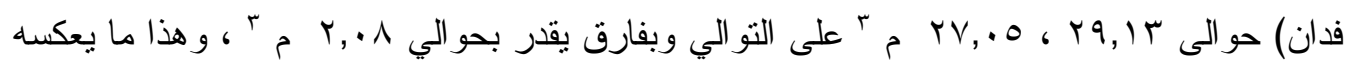
تحليل التباين من عدم وجود فروق معنوية في كميات السماد العضوي المضافة لفدان البطاطس للفئة

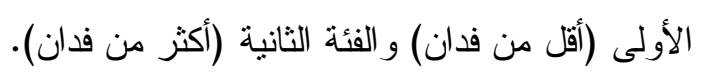

وفيما يتعلق بوحدات السماد الآزوتي يتبين عدم وجود اختلافات معنوية بين وحــدات الســماد

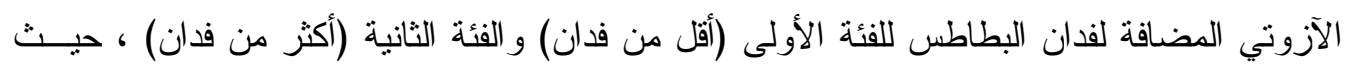

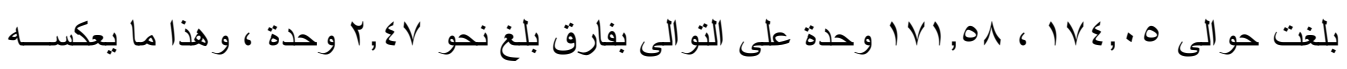
تحليل التباين من عدم وجود فروق معنوية في وحدات السماد الآزوتي المضافة لفدان البطاطس للفئة

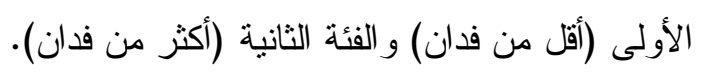

أما بالنسبة لوحدات الفوسفات المضافة للفدان من البطاطس فلا توجد اختلافات معنوية بـين

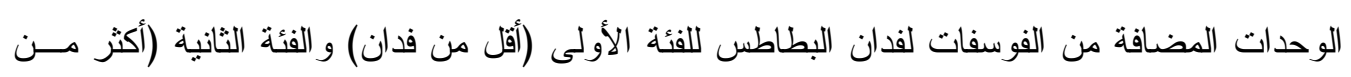

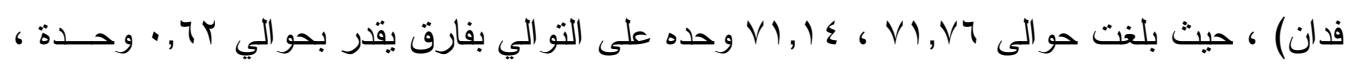

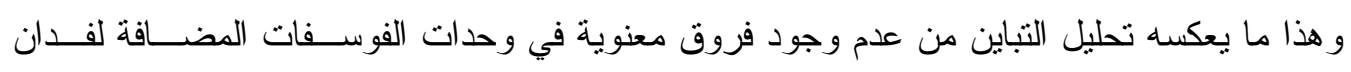

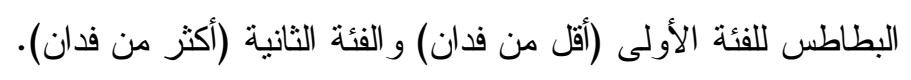

وبالنسبة لوحدات البوتاسيوم المضافة للفدان من البطاطس فلا توجد اختلافات معنويــة بــين

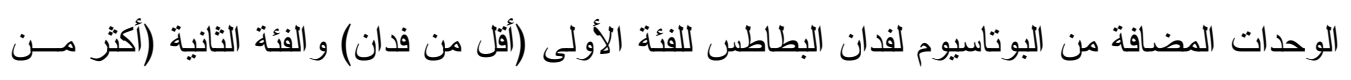

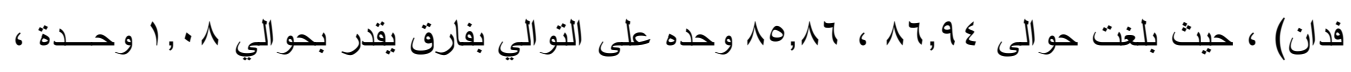

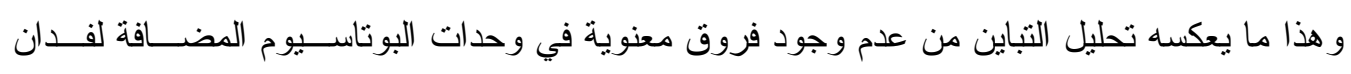

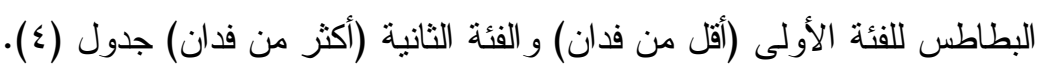
أما بالنسبة لكمية المبيدات المضافة تبين وجود اختلافات معنوية في الكميات المضافة لفــدان

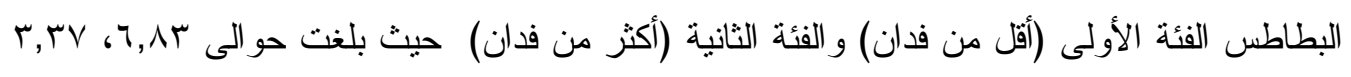

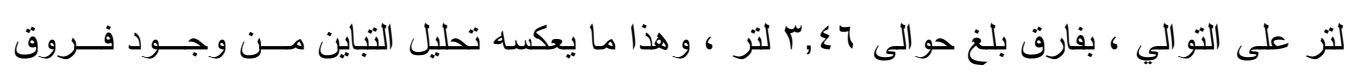

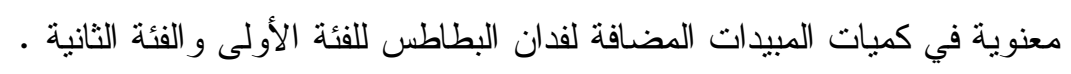

\section{أ- العمالة البشرية والآلية : البالية}

توضح بيانات جدول رقم (0) عدم وجود اختلافات معنوية في حجم استخدام العمل البشــرى

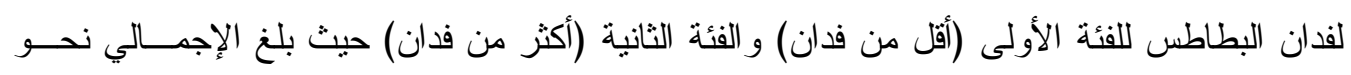

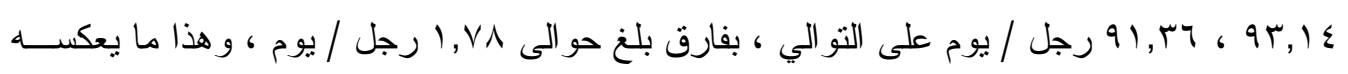

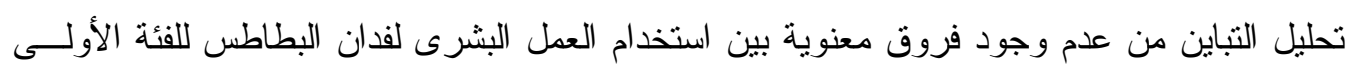
و الفئة الثانية . 
باستعر اض بيانات نفس الجدول تبين وجود اختلافات معنوية في استخدام العمل البشرى لفدان

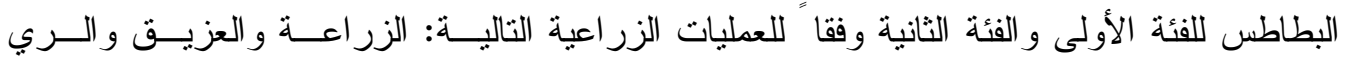

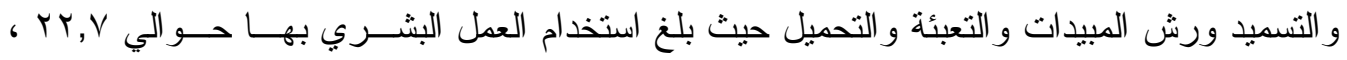

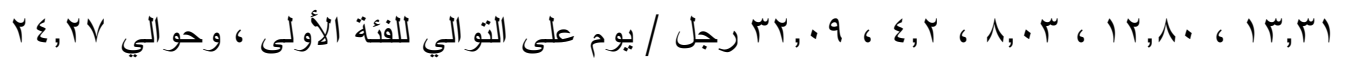

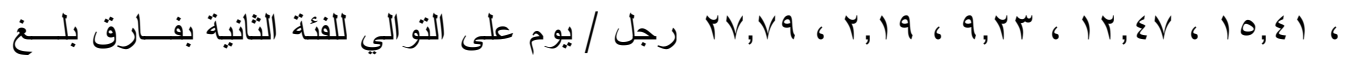

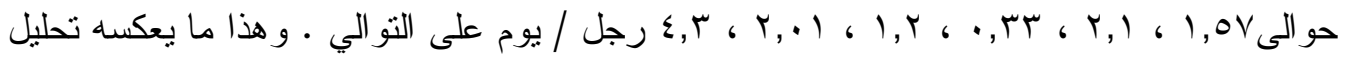
التباين من وجود فروق معنوية بين استخدام العمل البشرى لفدان البطاطس للفئة الأولى و الفئة الثانية وفقا للعمليات الزر اعية التالية: الزر اعة و العزيق و الري و التسميد ورش المبيدات و التعبئة و التحميـلـل ، حيث تعكس قيمة (F) معنوية تلك العمليات .

أمـا فيما يتعلق بالعمل الآلي فيتضح من بيانات نفس الجدول وجود فروق معنوية فـــي العـــلـ

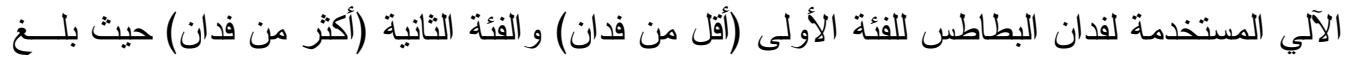

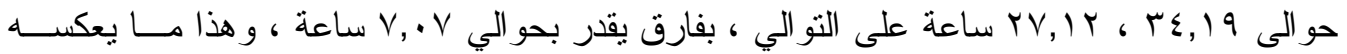
تحليل التباين من وجود فروق معنوية بين العمل الآلي المستخدم لفدان البطاطس للفئة الأولـــى الفئـــة

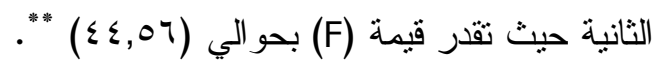

جدول رقم (0) : المتوسط القيزيقي لقوي العمل البشري والآلي لقدان البطاطس بعينة البحث

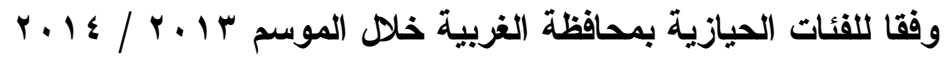

\begin{tabular}{|c|c|c|c|c|c|}
\hline $\mathbf{F}$ & الفارق & (أفثر من الثانية & (أقل من فذانة الأولى & & قوى العد \\
\hline$* *(r \wedge, 1 \curlyvee q)$ & $1,0 \mathrm{~V}$ & $r \leqslant, Y V$ & $r r, v$. & \multirow{7}{*}{ 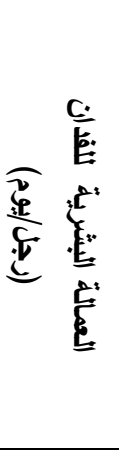 } & الزر اعة \\
\hline$* *(Y \curlyvee, \bullet \leq)$ & $r, 1$. & $10, \leqslant 1$ & $|r, r|$ & & العزيق \\
\hline$*(V, Y I)$ & 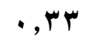 & $\mid r, \leqslant V$ & $1 r, \Lambda$. & & الري الري \\
\hline$* *(\wedge r, \bullet r \varepsilon)$ & $1, r$. & $9, Y r$ & $\Lambda, \cdot r$ & & التسميا \\
\hline$* *(r), \wedge r)$ & $r,+1$ & $r, 19$ & $\varepsilon, r$. & & رش المبيدات \\
\hline$* *(\Delta r, 0)$ & $\varepsilon, r$. & $r v, v q$ & rr,. q & & التعبئة و التحميل \\
\hline 1,0 & $1, \vee \wedge$ & $91, r q$ & $94,1 \leq$ & & الجثمالي العمل \\
\hline$* *(\wedge,, \bullet)$ & $1, r V$ & Ir,rr & $1 \leq, 7$ & \multirow{6}{*}{ 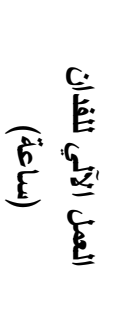 } & ماكينة ري \\
\hline$* *(09,01)$ & $r, \wedge r$ & $r, 91$ & $7, \wedge 1$ & & ماتور رش \\
\hline$* *(\leqslant 9,71)$ & 1,71 & $\varepsilon, Y r$ & 0,9 . & & خدمة الجرار \\
\hline$* *(I Y, V Y)$ & $1, r q$ & 0,09 & $\neg, \wedge \wedge$ & & جرار الحصاد \\
\hline$* *(\Gamma \cdot, \leqslant 1)$ & r, १^ & $9, \wedge$. & Ir,VA & & إجمالي الجرار \\
\hline$* *(\leqslant$ \&, ४ $)$ & $v, \cdot v$ & rV,Ir & $r \leq, 19$ & & إجمالي العمل الآلي \\
\hline
\end{tabular}


كما أنه يوجد إختلافات معنوية في استخدام العمل الآلي لفدان البطاطس للفئة الأولى (أقل من

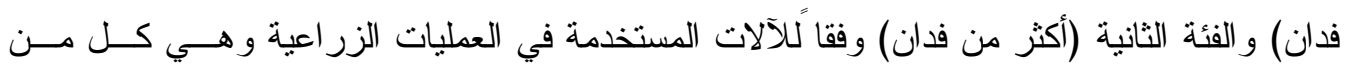
ماكينة الري ، ماتور الرش ، خدمة الجرار ، جرار الحصاد إلي وجود فروق معنوية ، حيث بلغ كل

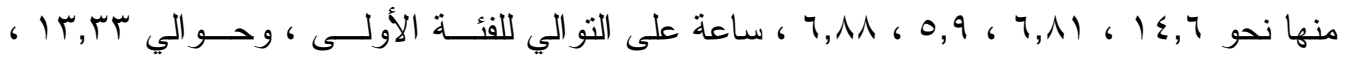

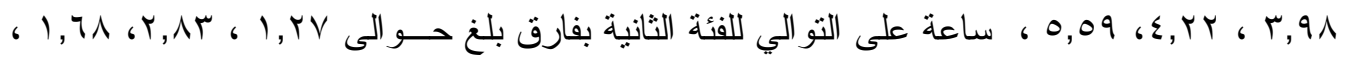

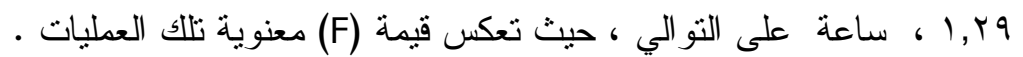
مما سبق يتضح وجود فروق معنوية بين التقاوى و المبيدات و العمل البشرى و العمل الالى لفدان

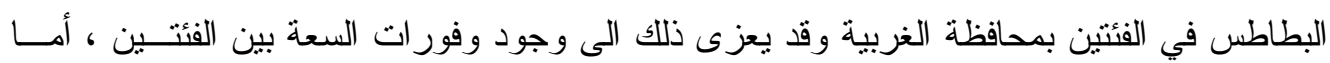
بالنسبة للأسمدة بكافة أنو اعها فلا توجد فروف معنوية بين الفئنين . ثانياً: التكاليف الإتتاجية الفدانية لمحصول البطاطس :

$$
\text { أ- التكاليف الكلية : }
$$

توضح بيانات جدول (T) أن متوسط التكاليف الإنتاجية الكلية لفدان البطاطس في الفئة الأولى

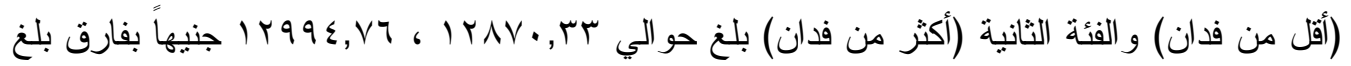

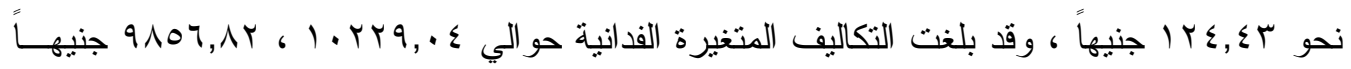

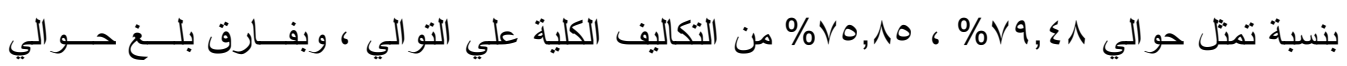

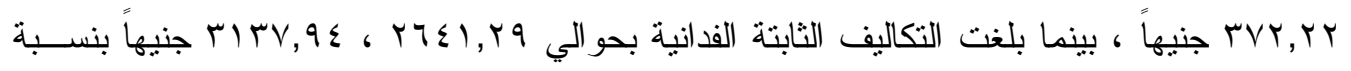

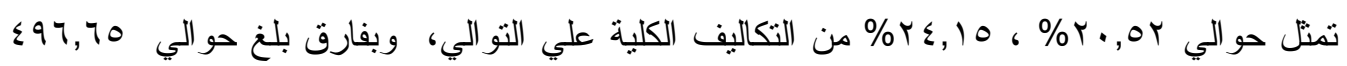
جنيهاً.

جدول رقم (T) : التكاليف الإتتاجية للفدان وللطن لمحصول البطاطس وفقا للفئات الحيازية

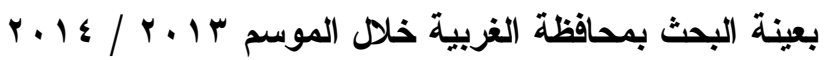

\begin{tabular}{|c|c|c|c|c|c|}
\hline $\mathbf{F}$ & الفارق & 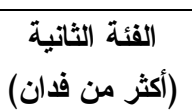 & (أقلّ من فدان) & \multicolumn{2}{|c|}{ التكاليف الإتتاجية } \\
\hline$* *(\curlyvee \wedge, \vee \leq)$ & rVY,Yr & 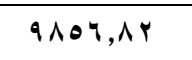 & 1.rrq, \& & \multirow{3}{*}{ 廌 } & التكاليف المتغيرة \\
\hline$* *(Y \bullet,\{\Upsilon)$ & ะ9४, ४० & rirv,q & $r q \leq 1, r q$ & & التكاليف الثابتة \\
\hline$* *(1 r, \Delta \Delta r)$ & $\mid r \leqslant, \leqslant r$ & $1 Y 99 \leqslant, V 4$ & IrAv.,rr & & التكاليف الكلية \\
\hline$* *(r \leq, \varepsilon)$ & $\cdot, r$. & $17,7 \leq$ & $17,9 \leq$ & \multirow{4}{*}{ E. } & متوسط انتاجية \\
\hline$*(\bullet, \diamond r Y)$ & $11, \leqslant \wedge$ & هQY,r & $\neg, \Gamma, \wedge \varepsilon$ & & التكاليف المتغيرة \\
\hline$* *(r q, r \leq r)$ & Tr,T & $\mid \wedge \wedge, \diamond \wedge$ & 100,94 & & التكاليف الثابتة \\
\hline$* *(Y \cdot, \leqslant r r)$ & $r 1,11$ & $\vee \wedge \cdot, q \leqslant$ & V०q,V४ & & التكاليف الكلية \\
\hline
\end{tabular}

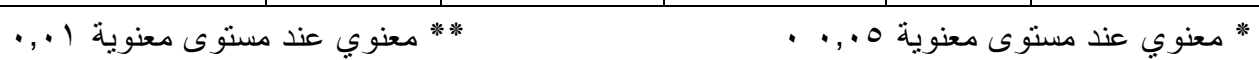

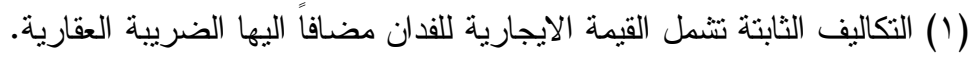

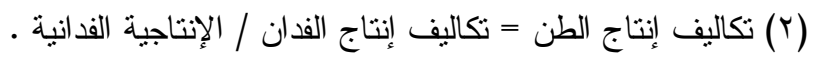
المصدر: جمت وحسبت من بيانات العينة الميدانية. 
و هذا ما يعكسه تحليل التباين من وجود فروق معنوية بين الفئة الاولــى و الثانيــة لمتغيــر ات التكاليف الكلية و المتغيرة و الثابتة لفدان البطاطس في كل من الفئة الأولى (أقل من فدان) و الفئة الثانية

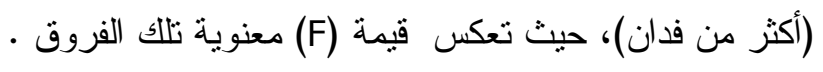

\section{التكاليف الإنتاجية للطن من البطاطس :}

بلغت الإنتاجية الفدانية لمحصول البطاطس في الفئة الأولى (أقل من فدان) حوالي ع 9,7 9 طن

$$
\text { / فدان ، وحوالي ع 7,7 أطن / فدان في الفئة الثانية (أكثر من فدان). }
$$

وتثير بيانات جدول (ج) إلي أن متوسط التكاليف الكلية لطن البطاطس النــاتج فـــي الفئــة

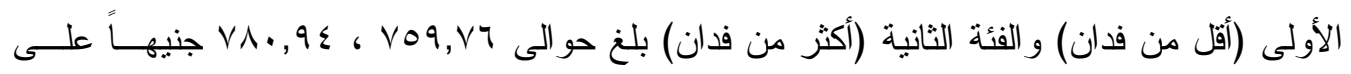

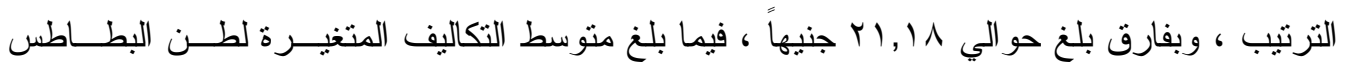

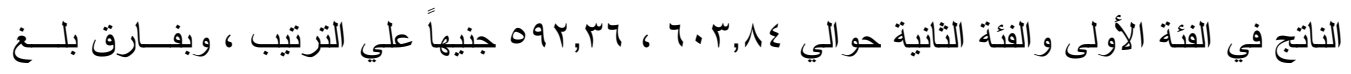

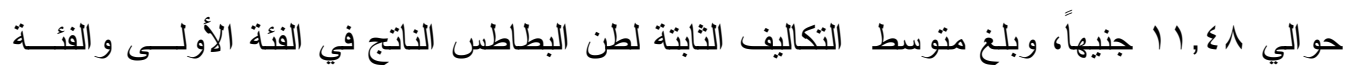

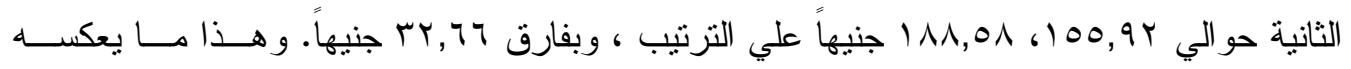

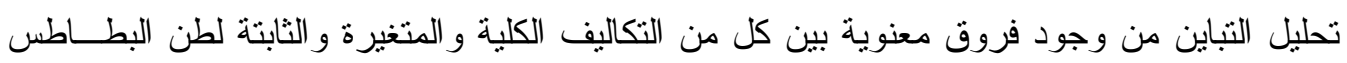

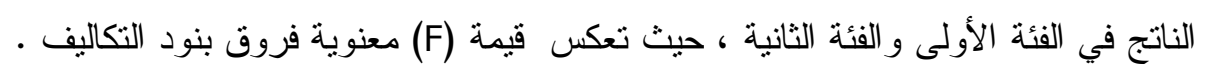

\section{ب- التكاليف الإنتاجية القدانية المتغيرة لمحصول البطاطس :}

$$
\text { 1 - تكاليف مستلزمات الإتتاج : }
$$

توضح بيانات جدول (V) عدم وجود اختلافات كبيرة في تكلفة مســنلزمات الإنتــاج لفــدان

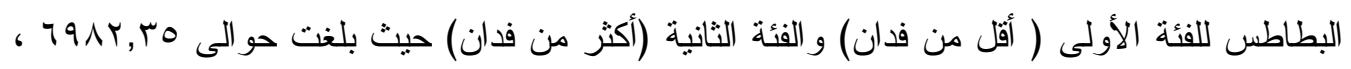

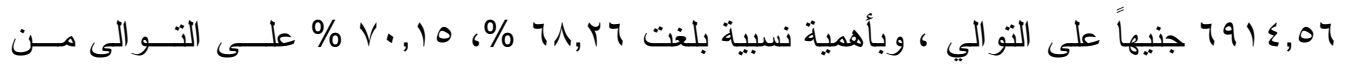

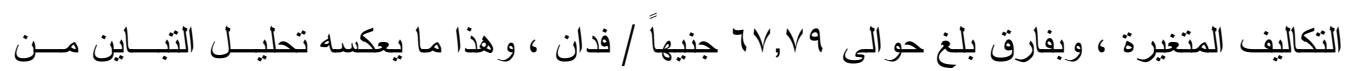

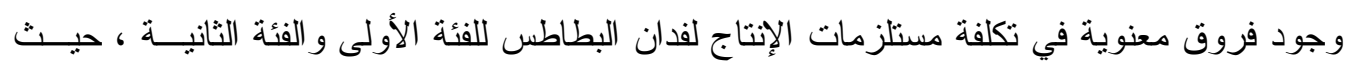

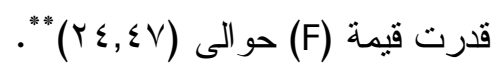

وباستعر اض تكلفة مستلزمات الإنتاج فتبين من بيانات جدول (V) وجود اختلافات معنوية بين

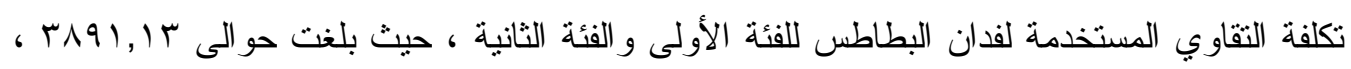

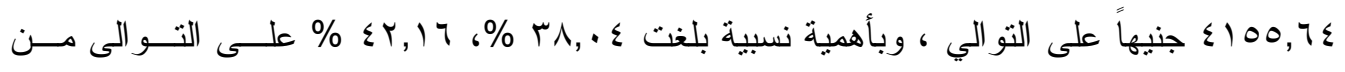

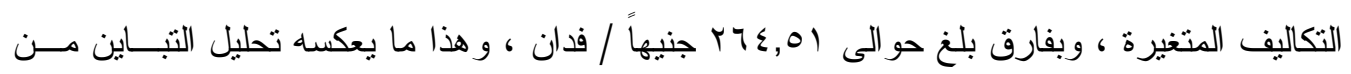

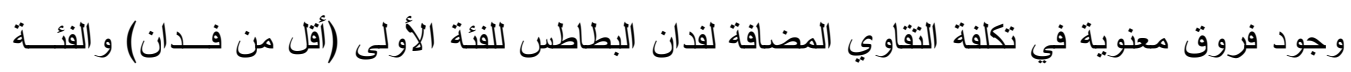

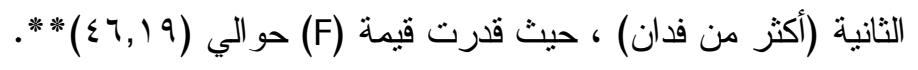


جدول رقم (V) : التكاليف الإتتاجية الفدانية للمستلزمات الإتتاجية للفدان من البطاطس بالجنيه

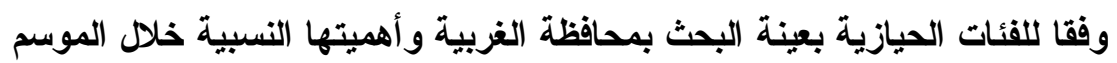

$r \cdot 1 \leq / r \cdot 1 r$

\begin{tabular}{|c|c|c|c|c|c|c|}
\hline \multirow[b]{2}{*}{$\mathbf{F}$} & \multirow{2}{*}{ الفارق } & \multicolumn{2}{|c|}{ (أكثر من فئة الثانية } & \multicolumn{2}{|c|}{ (أفل من فدانة الأولى } & \multirow{2}{*}{ مستلزمات الإنتاج } \\
\hline & & $\%$ & (جنيلة) & $\%$ & (التكلفة & \\
\hline$* *(\leqslant 7,19)$ & YY\&,01 & $\leqslant Y, 17$ & $\leq 100,7 \leqslant$ & $r \wedge, \cdot \varepsilon$ & $r \wedge q 1,1 r$ & التقاوي \\
\hline$* *(19,9 \wedge)$ & $\Delta V, \varepsilon r$ & $\wedge, \cdot 1$ & $\vee \wedge 9,0 \leq$ & $\Lambda, \Upsilon \wedge$ & $\Lambda \leq 7,97$ & السماد بلاي \\
\hline$* *(Y \vee, \leq \searrow)$ & rY,Or & $\wedge, \wedge$. & ง ษ , \&. & $\wedge, \vee$. & $\wedge \wedge q, q r$ & السماد \\
\hline$* *(9 \vee, \cdots)$ & $\bullet \bullet, r$. & $r, 0 q$ & צד, זهr & $\varepsilon, \ldots$ & $\varepsilon .9,17$ & السماد \\
\hline$* *(9 \vee, 10)$ & ه & 7,70 & $\Upsilon 00, \leqslant \Lambda$ & 7,91 & $V \cdot \neg, \wedge r$ & البوتادي \\
\hline$* *(19,7 \%)$ & $1 \leq 0,79$ & $\cdot, 9 \leq$ & Q Q & r,rr & $r r \wedge, r \leq$ & المبيدات \\
\hline$* *(৭ \leq, \wedge \leq)$ & r. & $r q, \wedge 0$ & r $q \leq r, Y q$ & $r u, V \leq$ & $r Y \leq Y, V I$ & إجمالي العمل \\
\hline$* *(r \leq, \leq V)$ & $\neg \vee, \vee q$ & $v \cdot, 10$ & $791 \leq, 07$ & $\checkmark \wedge, Y \uparrow$ & $\neg 9 \wedge r, r \varepsilon$ & إلإنتات \\
\hline$* *(\curlyvee \wedge, \vee \leq)$ & rVr, rr & $1 \ldots, \ldots$ & 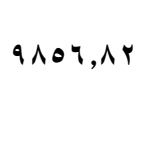 & $1 \ldots, \ldots$ & 1.rrq,.0 & التكاليف \\
\hline
\end{tabular}

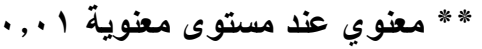

المصدر : جمعت وحسبت من بياتات العينة الميدانية.

وتشير بيانات جدول (V) أنه نوجد اختلافات معنوية بين تكلفة كل من السماد البلدي ، السماد الآزوتي ، السماد الفوسفاتي ، والسماد البوتاسي المضافة لفدان البطاطس للفئة الأولى (أقل من فدان)

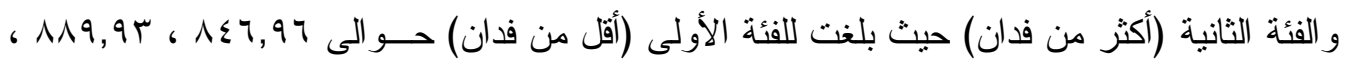

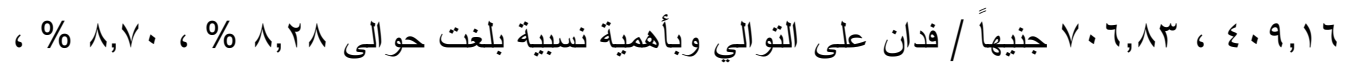

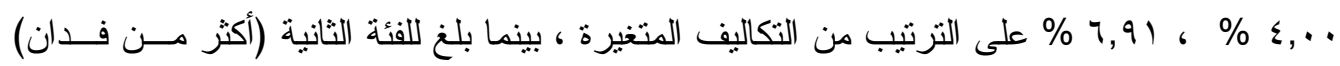

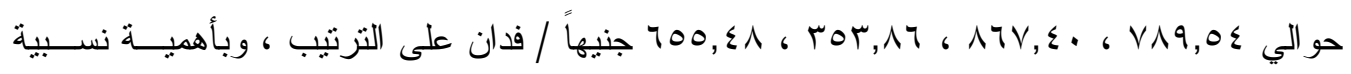




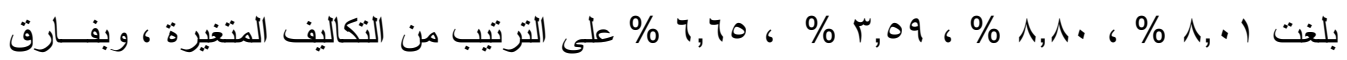

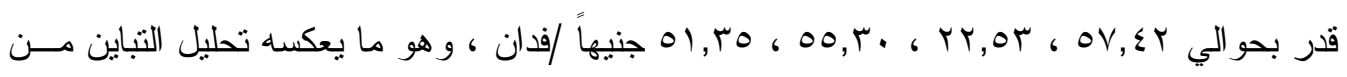
وجود فروق بين تكلفة كل من السماد البلدي و السماد الآزوتي و السماد الفوسفاتي و السماد البوتاســي المضاف لفدان البطاطس للفئة الأولى و الفئة الثانية ، حيث تعكس قيمة (F) معنويــة الفــروق بــين مستلزمات الانتاج.

أما بالنسبة لتكلفة المبيدات فيتضح من بيانات نفس الجدول وجود اختلافات معنوية بين تكلفــة

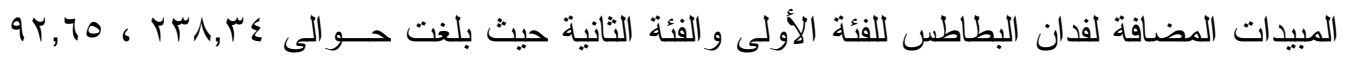
جنيهاً / فدان على الترتيب ، وبأهمية نسبية بلغت حو الى بr, ب \% ، ؟ 9, ، \% من التكاليف المتغيرة على التزتيب ، وبفارق بلغ حو الى 19 ـ 1 ا جنيهاً ، و هذا ما يعكسه تحليل التباين من وجود فــروق معنوية بين تكلفة المبيدات المضافة لفدان البطاطس للفئة الأولى و الفئة الثانية، حيث قدرت قيمــة (F)

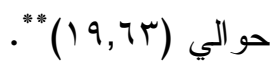

\section{r - تكاليف العمالة البشرية والآلية :}

توضح بيانات جدول (^) وجود اختلافات معنوية في تكلفة العمل البشرى المستخدمة لفــدان

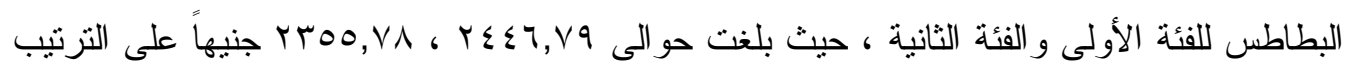

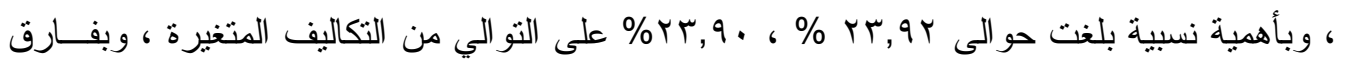

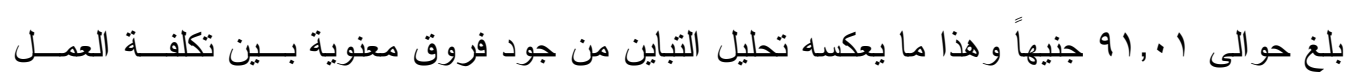
البشرى لفدان البطاطس للفئة الأولى و الفئة الثانية. 
جدول رقم (^): التكاليف الإتتاجية الفدانية لقوي العمل البشري والآلي للفدان من البطاطس

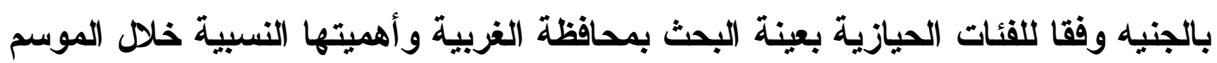
$r+1 \leqslant / r+1 r$

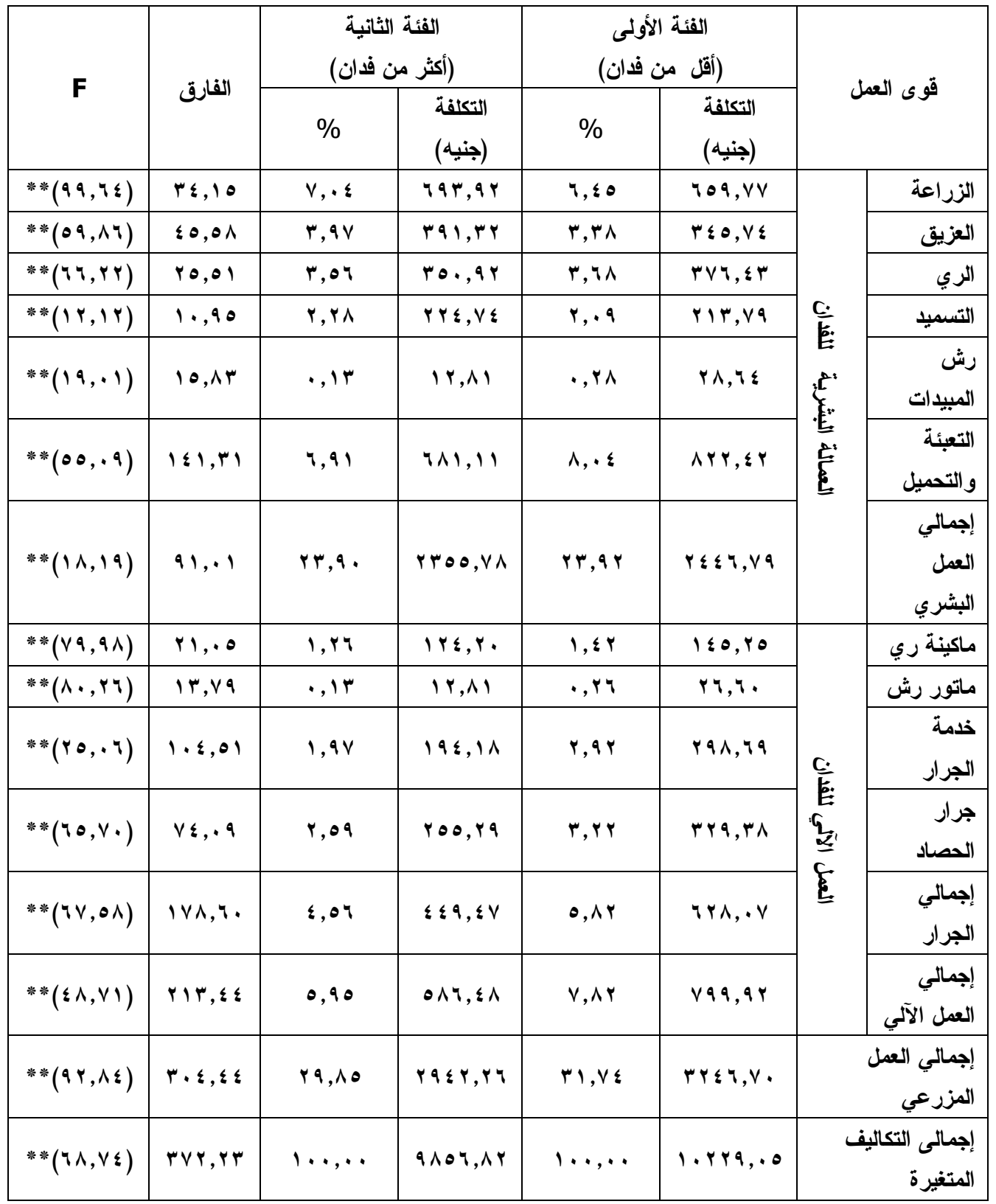

"* مغنوي عند مستوى معنوية ا +,.

المصدر: جمعت وحسبت من بياتات العينة الميدانية.

وباستعر اض تكلفة العمل البشري وفقا للعمليات الزر اعية فتشير بيانات نفـس الجــدول إلــى

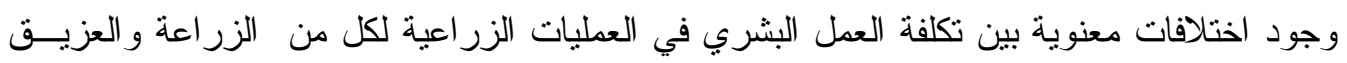
و الري و التشميد ورش المبيدات و التعبئة و التحميل لفدان البطاطس للفئة الأولى (أقل من فدان) و والفئة

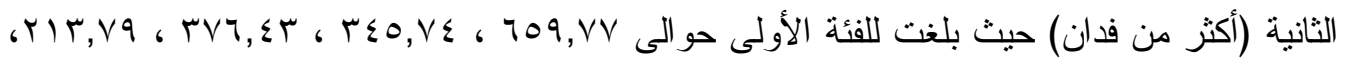




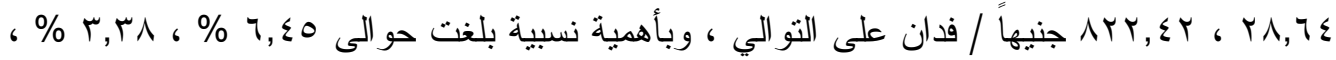

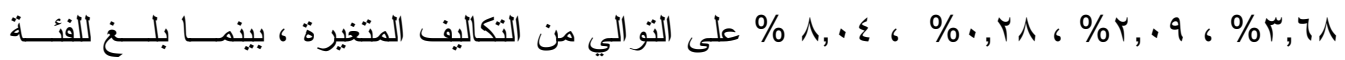

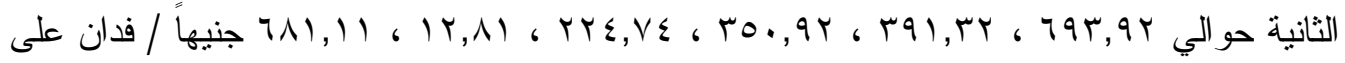

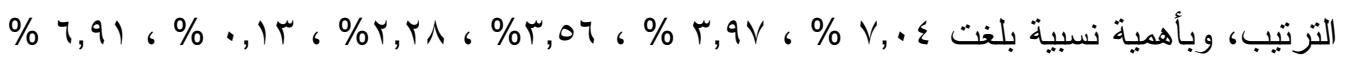

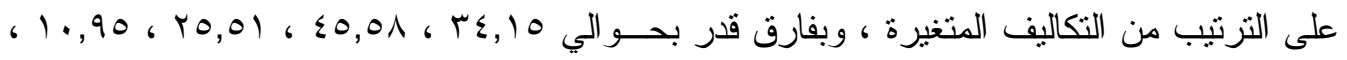

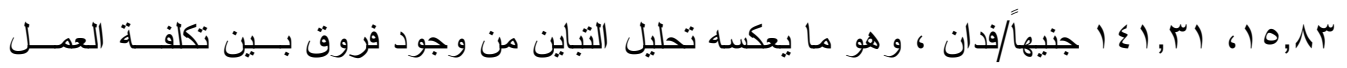

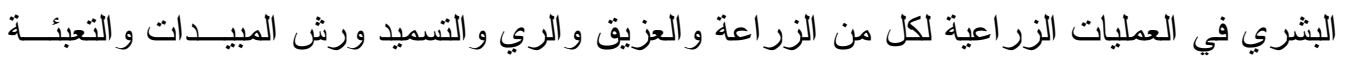

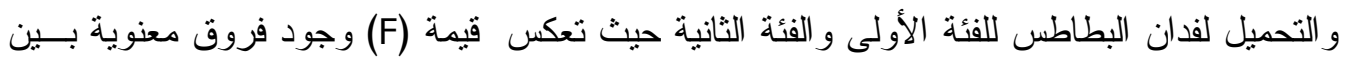
تكلفة العمل البشرى فى العمليات الزر اعية المذكورة ـ

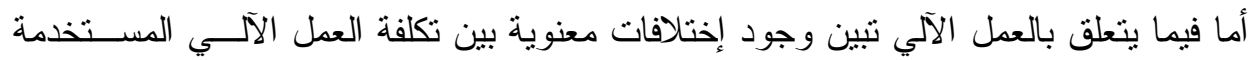

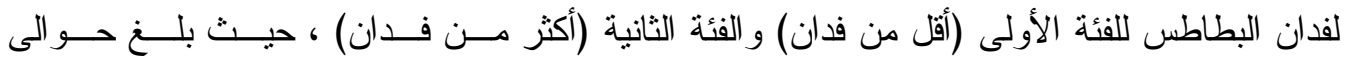

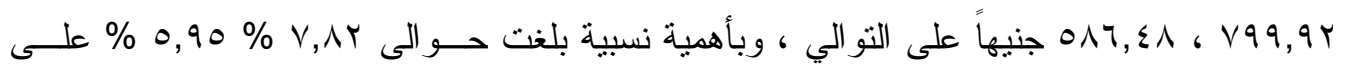

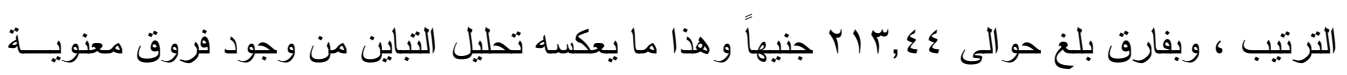
في تكلفة استخدام العمل الآلي لفدان البطاطس للفئة الأولى و الفئة الثانية . وباستعر اض تكلفة العمل الآلي وفقا للآلات المستخدمة في العمليات الزراعية تبين وجود

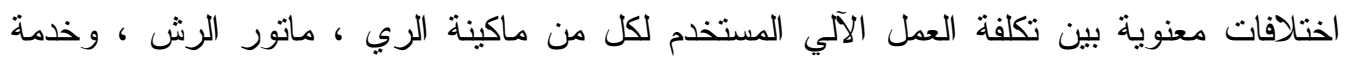

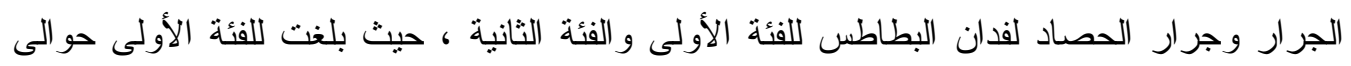
Y

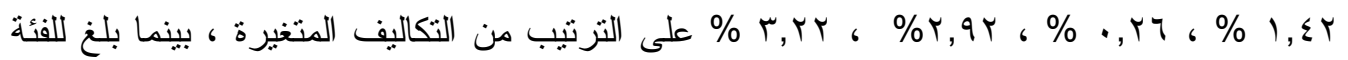

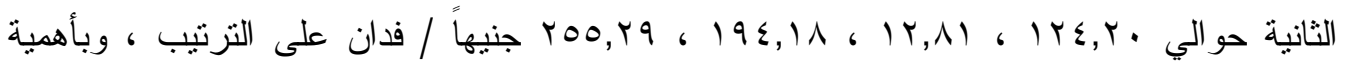

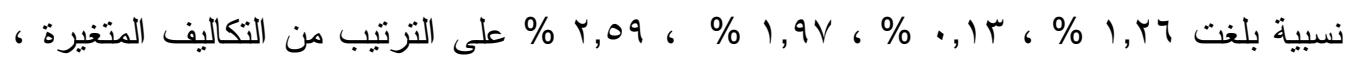

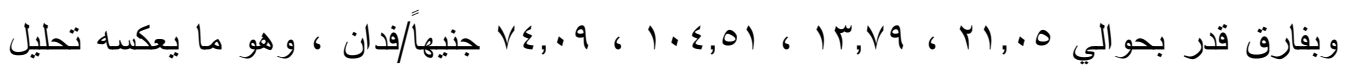

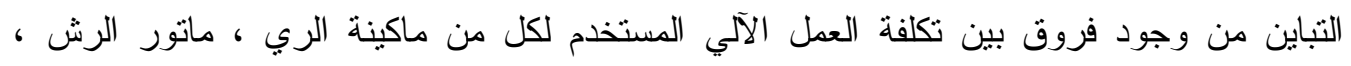

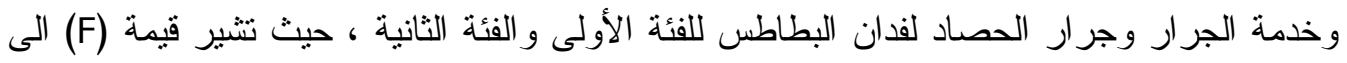
وجود فروق معنوية بين تكلفة العمل الالى للالات المستخدمة.

أما بالنسبة لإجمالي تكلفة العمل المزرعي (البشري و الآلي) اتضح وجود اختلافات معنوية في

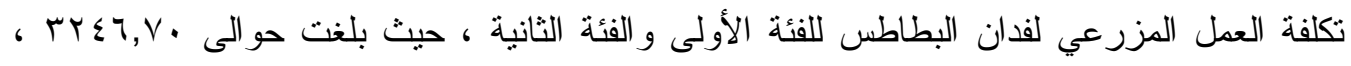

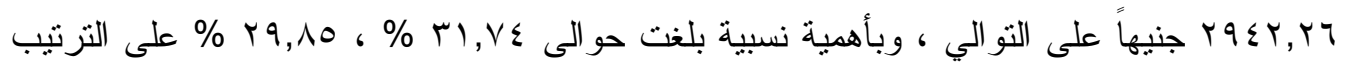

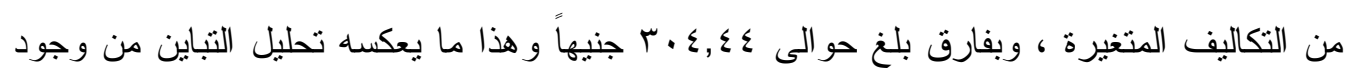
فروق معنوية بين تكلفة العمل المزرعي للفدان من البطاطس للفئة الأولى (أقل من فدان) و الفئة الثانية

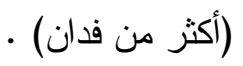


مما سبق ينتين وجود اختلافات معنوية بين اجمالى تكلفة مستلزمات انتاج الفدان من البطاطس فى الفيتنين ، وقد يعزى ذلك الى الافراط فى استخدام مستلزمات الانتاج فى الفئة الاولى ذات الحيازات الصغيرة عن الفئة الثانية ، اما بالنسبة لتكلفة العمل البشرى و الالى فقد تبين وجود فروق

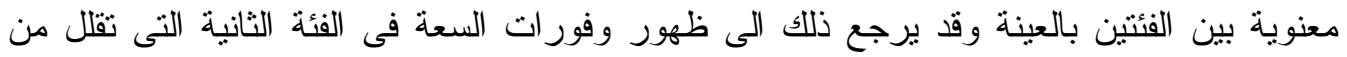
حجم العمالة البشرية وعدد ساعات العمل الالى فى الئة الثانية عن الاولى مما يقلل التكاليف المتغيرة.

\section{الكفاءة الاقتصادية لإنتاج محصول البطاطس بعينة البحث بمحافظة الغربية}

تعرف الكفاءة الإقتصادية علي أنها : الحصول علي نفس القدر من الناتج بتكلفة أقل ، أو الحصول علي ناتج اكبر بنفس التكلفة حيث تتحقق الكفاءة الإقتصادية لعنصر ما بتساوي فيمة الناتج

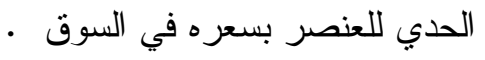

تم إجر اء تقدير دوال الإنتاج بأكثر من طريقة وكانت أفضلهم من الناحية الإقتصادية الطريقة

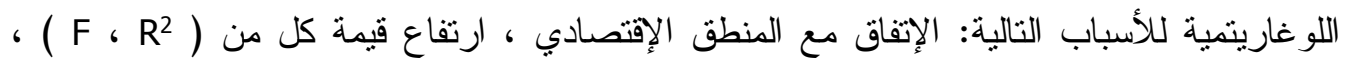
و الإشار ات في الدالة ـ وقد نم إدخال مجموعة من العوامل في كل دالة إنتاج : كمية العمل البشري (رجل/يوم) ، عدد ساعات الري (ساعة) ، كمية التقاوي المستخدمة (كجم) ، كمية السماد الأزوتي (بالوحدة) ، كمية السماد الفوسفاتي (بالوحدة) ، وتم اختيار العو امل المعنوية فقط.

\section{(1 ) الفئة الأولى (أقلّ من فدان):}

بدر اسة الدالة الإنتاجبة رقم (1) بالجدول (9) للفئة الأولى (أقل من فـدان) و التــي توضــح

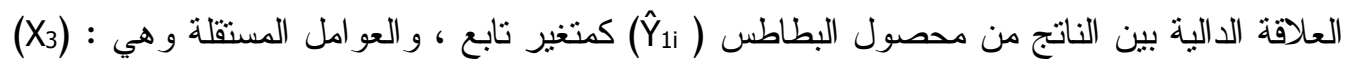

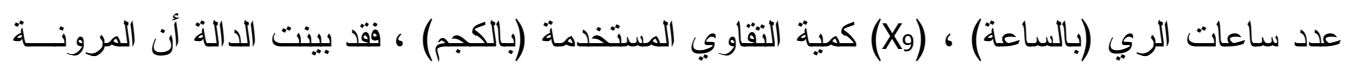
الإتتاجية الإجمالية بلغت نحو 99, • مما يعني سيادة العلاقة الإنتاجية المتتاقصة أي ينز ايد فيها الناتج

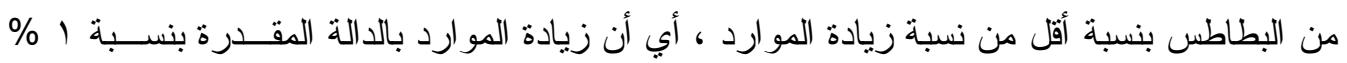

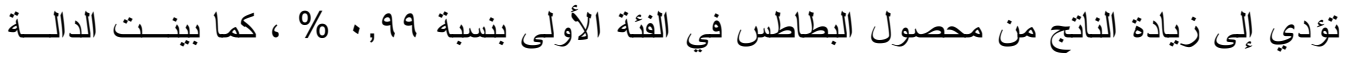

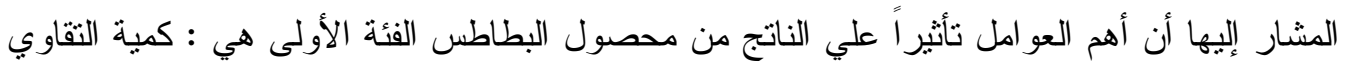

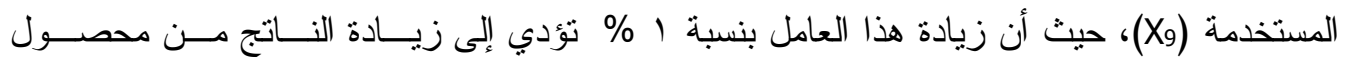

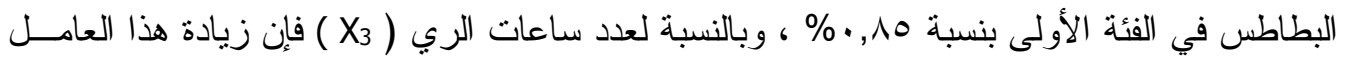

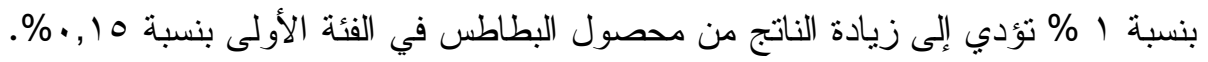

وتوضح قيمة (ت) معنوية معاملات الانحدار عند مستوي ا.,. ، ، كما أن جميع المعاملات موجبة وتقل عن الو احد الصحيح مما يعني أن استخدام هذا العنصر يقع في المرحلة الثانية من قانون تناقص الغلة.

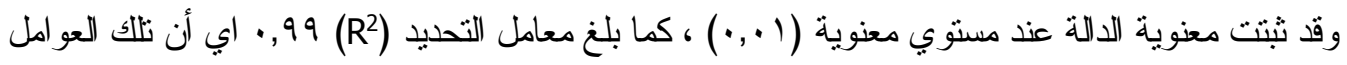
المشار إليها تقسر نحو 99\% من العو امل المؤثرة على الناتج من محصول البطاطس في الفئة الأولى . 


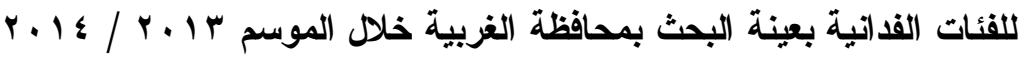

\begin{tabular}{|c|c|c|c|c|c|}
\hline $\mathbf{F}$ & $\mathbf{R}^{2}$ & المرونة & المعادلة المقدرة & النميازي & p \\
\hline$(368) * *$ & 0.99 & 0.999 & $\begin{array}{r}L \hat{Y}_{1 \mathrm{i}}=-1.351+0.153 \mathrm{LX}_{3 \mathrm{i}}+0.846 \mathrm{LX} \mathrm{X}_{9 \mathrm{i}} \\
(3.409)^{* *}(19.348)^{* *}\end{array}$ & (أقلّة الأولى من & 1 \\
\hline$(338) * *$ & 0.98 & 0.495 & $\begin{array}{l}L \hat{Y}_{2 i}=0.707+0.33 L X_{2 i}+0.147 L X_{3 i}- \\
0.264 L X_{11 i}+0.282 L X_{12 i} \\
\quad(2.186) * \\
(1.809) \quad(2.183)^{*}\end{array}$ & (ألفئة الثانية & $r$ \\
\hline
\end{tabular}
= $\hat{\mathbf{Y}}_{\mathbf{1 i}}$ القيمة التقايرية لإجمالي الناتج في الفئة الثانية لمحصول البطاطس.

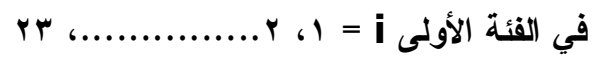
= LX2i

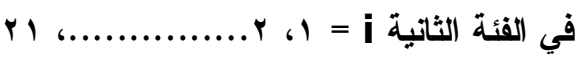
= LX $=\mathbf{L X}_{\mathbf{3 i}}$ = LX $=$ = كمية السماد الآزوتي المضافة (بالوحدة). = LX $=$ Sمية التقاوي المستخدمة (بالكجم). = LX12i المصدر : جمت وحسبت من بيانات العينة الميانية.

وبدر اسة النوزيع الوظيفي للناتج من محصول البطاطس في الفئة الأولى على الموارد الأنتاجية التى

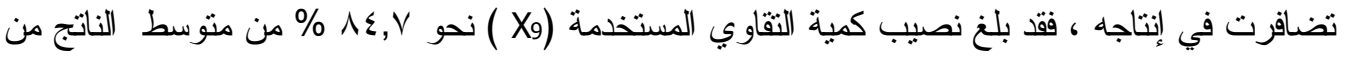

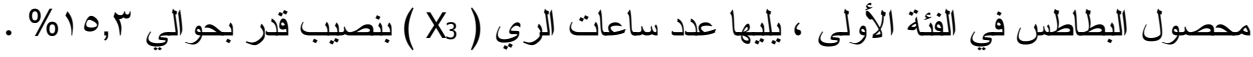
وبتقدير قيمة الناتج الحدي لهذه المو ارد وذلك بضرب الناتج الحدي للمورد في متوسط ســر

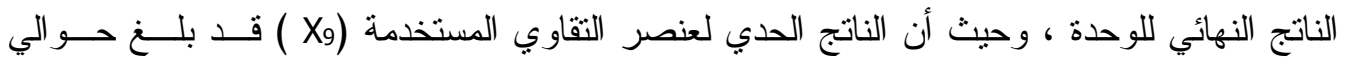

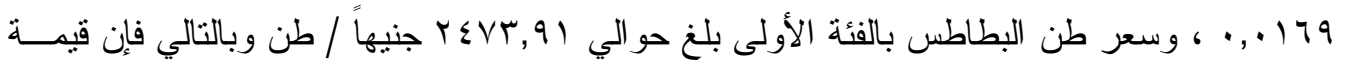
الناتج الحدي لعنصر التقاوي المستخدمة (X9) ) بالكجم قد بلغت حو الي (1, إك جنيهاً ، في حين كان

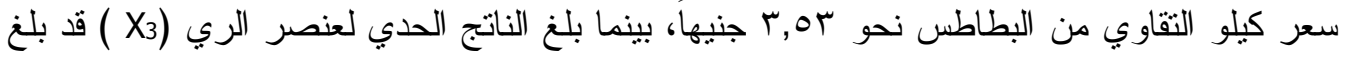

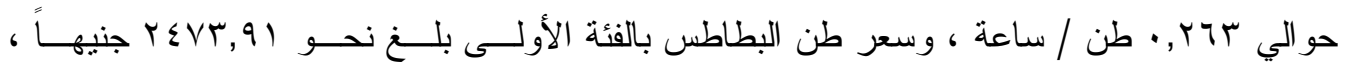

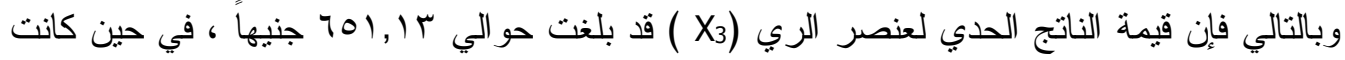

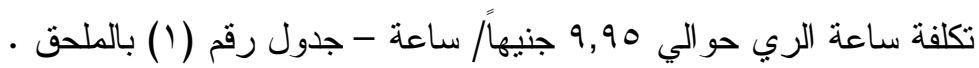
مما سبق يتضح أن شرط الكفاءة الاقتصادية قد تحقق على مستوى إجمالي الموارد طالمــا أن هنالك زيادة في الناتج من محصول البطاطس في الفئة الأولي ، ولكنها أقل من نســبة الزيــادة فــي لـي 
المو ارد، حيث كانت العلاقة الإنتاجية متتاقصة ـ أما بالنسبة لكل مورد على حده فقد تحقـق شـرط

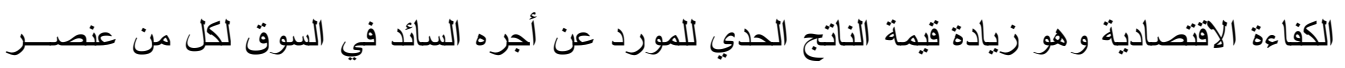
التقاوي (X9 ) ) ، و عنصر الري (X3 ) ) ، ولكن لاز ال بالإمكان زيادة هذه الكفاءة بزيادة عناصر الإنتاج

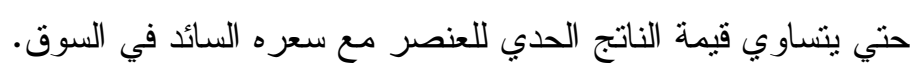

\section{(الفئة الثانية (أكثر من فدان):}

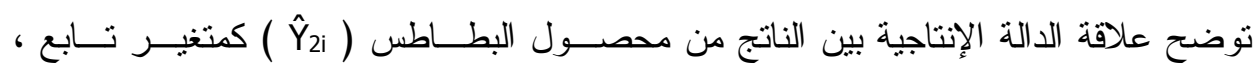

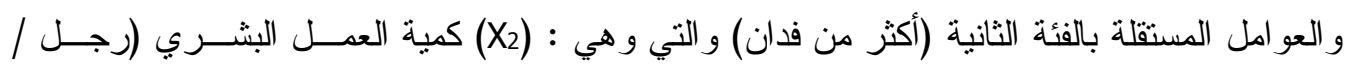

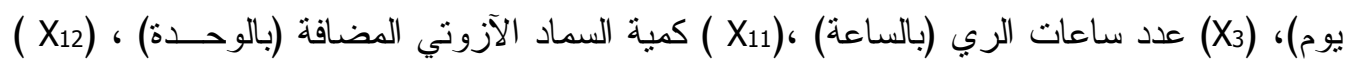

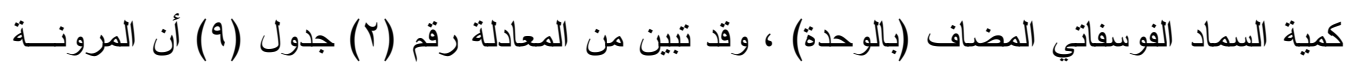

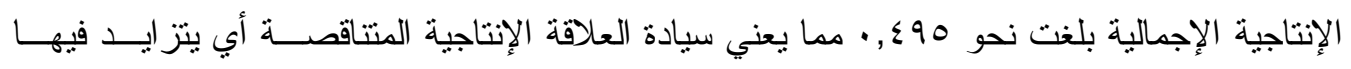

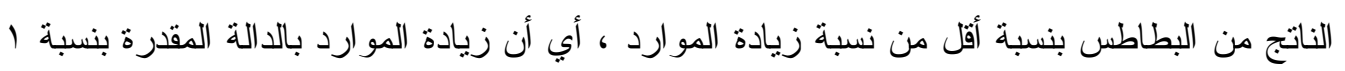

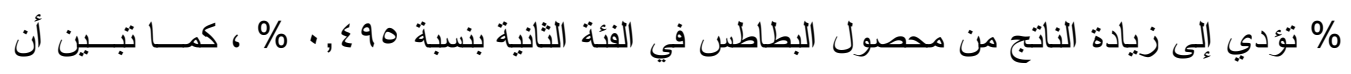

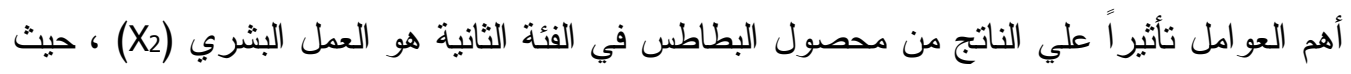

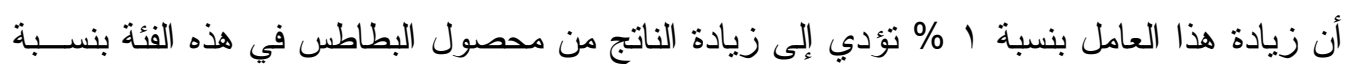

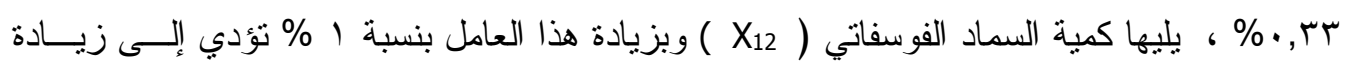

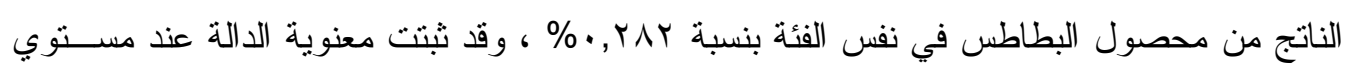

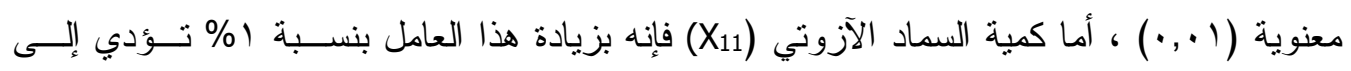

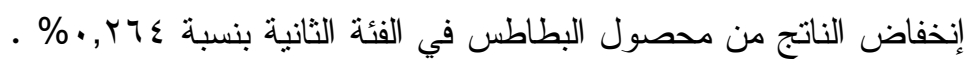

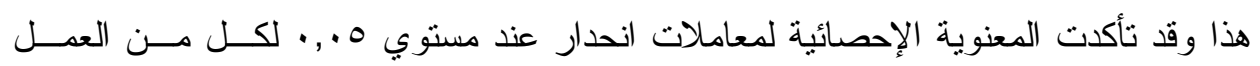

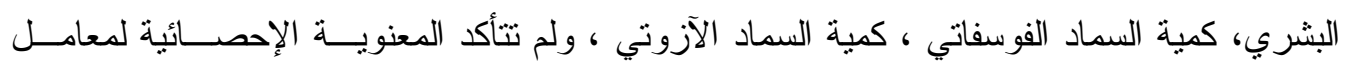

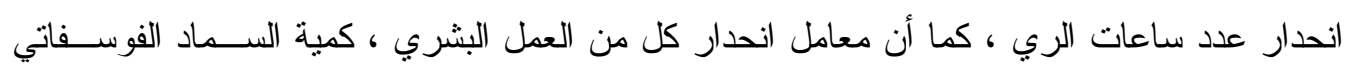

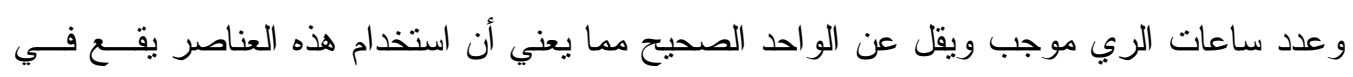

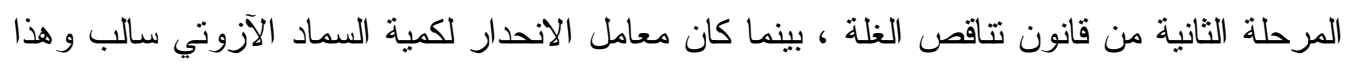

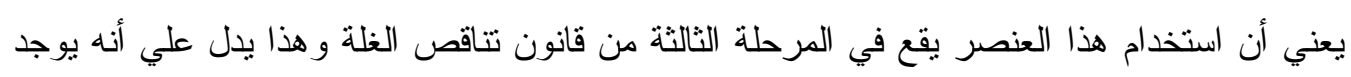

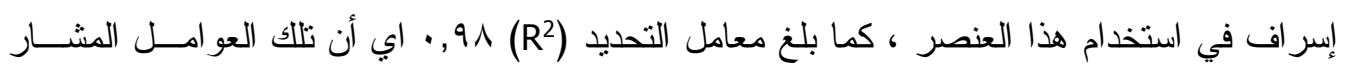

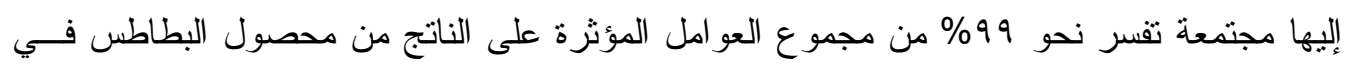
الفئة الثانية .

وبدر اسة التوزيع الوظيفي للناتج من محصول البطاطس في الفئة الثانية على الموارد الأنتاجية

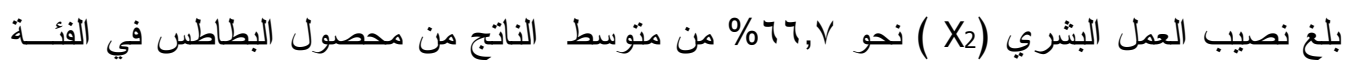

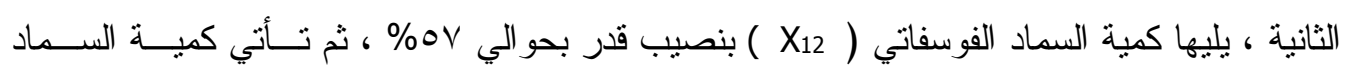

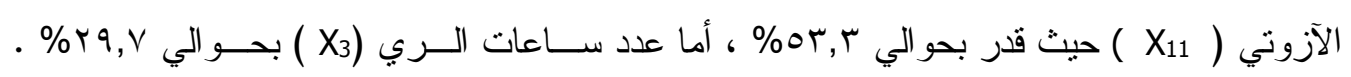

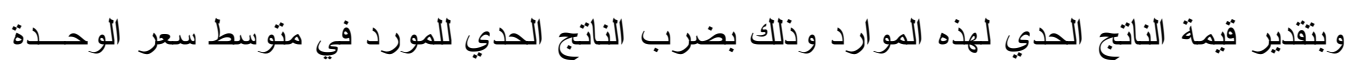


من الناتج النهائي ، وحيث أن الناتج الحدي للعمل البشري (X2 ) قد بلغ حسـو الي بr ـ ا , . ، وســر

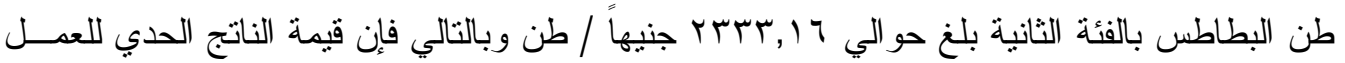

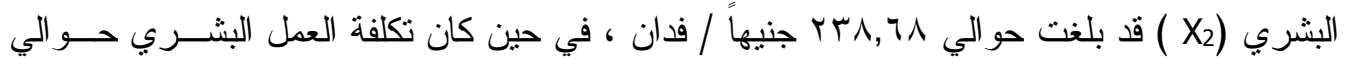

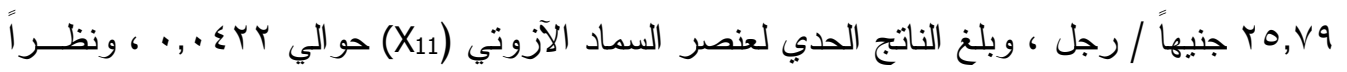

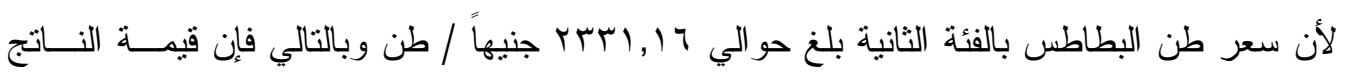

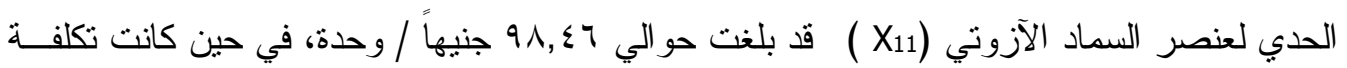

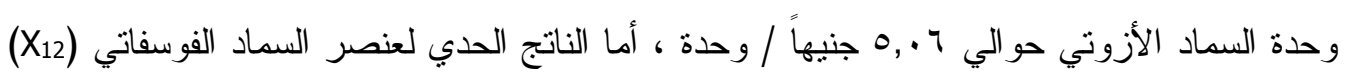

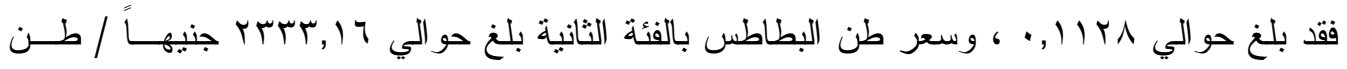

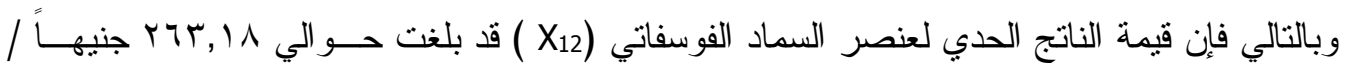

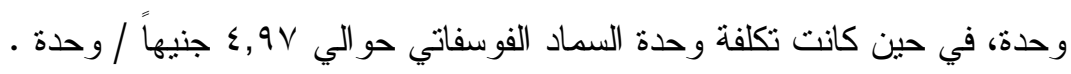

مما سبق يتضح أن شرط الكفاءة الاقتصادية قد تحقق على مستوى إجمالي الموارد طالمـــا أن

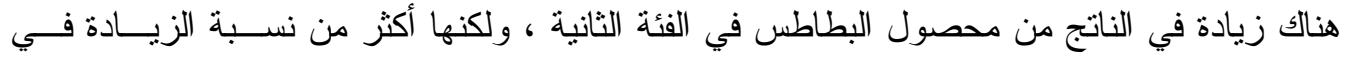

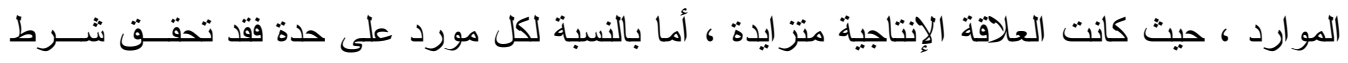

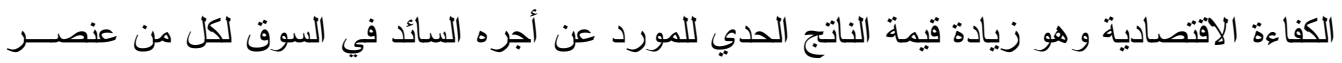

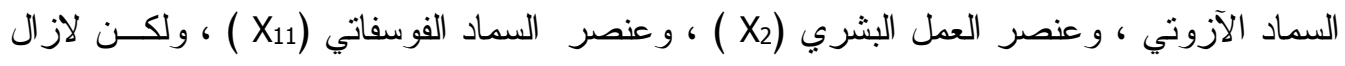

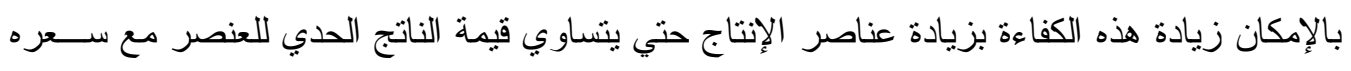
السائد في السوق.

\section{دوال تكاليف إنتاج محصول البطاطس فى محافظة الغربية.}

\section{1 - دالة تكاليف إنتاج البطاطس فى الفئة الأولى بعينة البحث .}

تعرف دالة تكاليف الإنتاج بأنها التكاليف الكلية دالة في النــاتج ، وبدر اســـة تكــاليف انتــاج

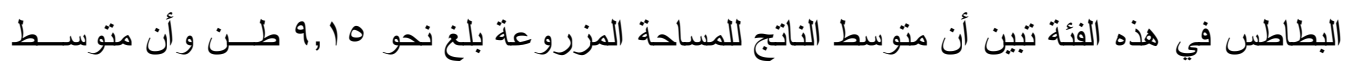

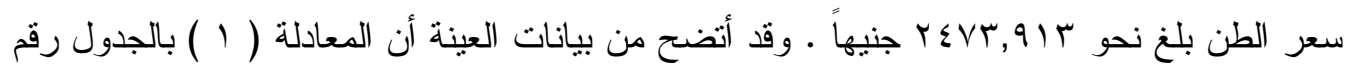

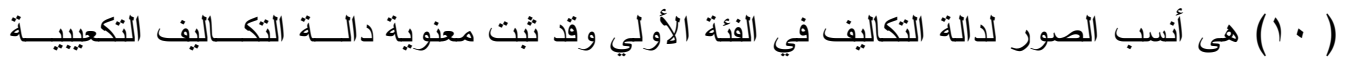

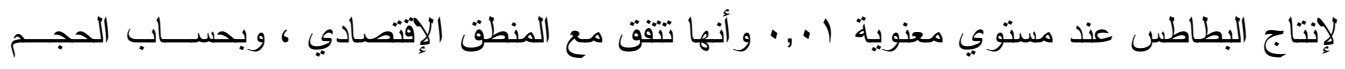

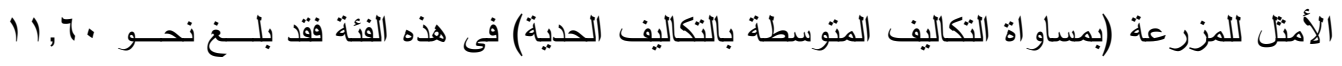

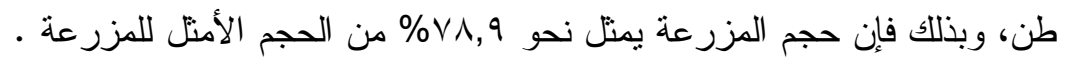

كما بينت الدالة المشار اليها أن الحجم الذى يعظم الربح للمزرعة (وذللك بمســاو اة التكـاليف

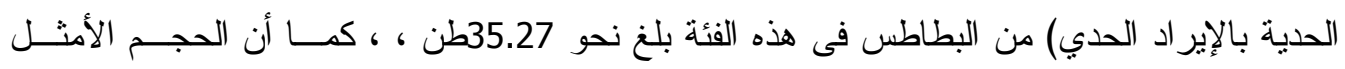

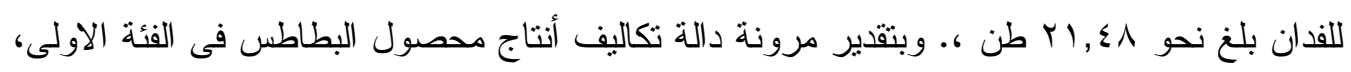

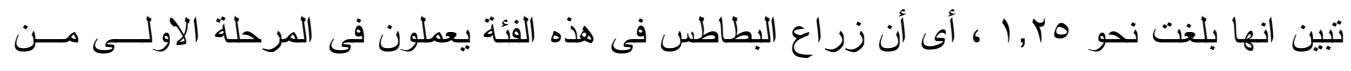

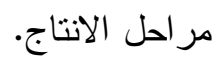




\section{r - دالة تكاليف إنتاج البطاطس فى الفئة الثاتية بعينة البحث .}

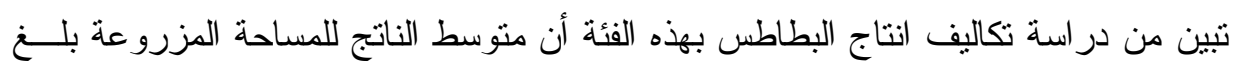

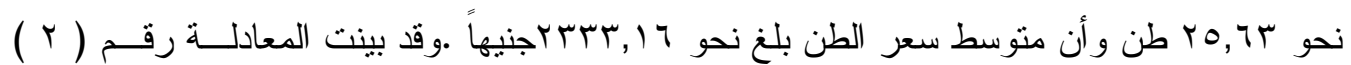

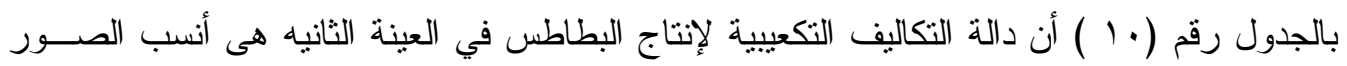

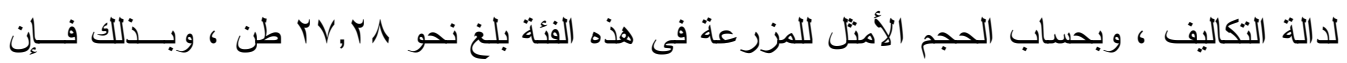

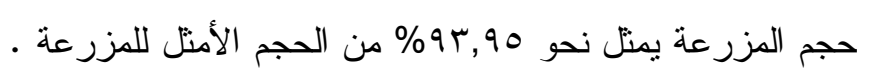

جدول رقم ( • 1) : دوال تكاليف إنتاج محصول البطاطس في فئتي عينة البحث بمحافظة الغربية

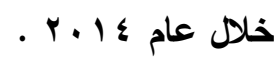

\begin{tabular}{|c|c|c|c|c|}
\hline المعنوية & قليمسة (F) & $R^{2}$ & دالة التكاليف & الفئة \\
\hline ** & 227.12 & 0.97 & $\begin{array}{l}T c_{1 i}=1426.295+577.135 Y_{i}-2.113 Y \\
2_{i}+0.548 Y^{3}{ }_{i} \\
\quad(2.696)^{*}(-0.077)(0.532)\end{array}$ & الأولي \\
\hline ** & 1536.19 & 0.99 & $\begin{array}{l}\mathrm{T} \mathrm{C}_{2}=4832.433+594.10 \mathrm{Y}_{\mathrm{i}}-5.895 \mathrm{Y}^{2}{ }_{\mathrm{i}} \\
+0.227 \mathrm{Y}^{3}{ }_{\mathrm{i}} \\
\quad(20.017)^{* *}(-8.767)^{* *}(6.212)^{* *}\end{array}$ & الثانية \\
\hline
\end{tabular}

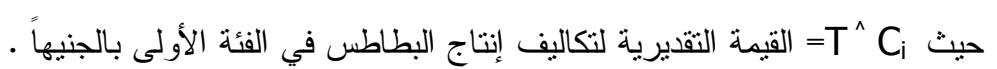
القيمة التقديرية لتكاليف إنتاج البطاطس في الفئة الثنانية بالجنيهاً . TC2

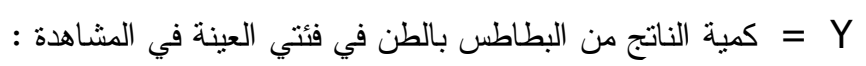
المصدر: جمت وحسبت من بياتات العينة الميدانية.

كما بينت الدالة المشار اليها أن الحجم الذى يعظم الربح للمزرعة من البطاطس فى هذه الفئة

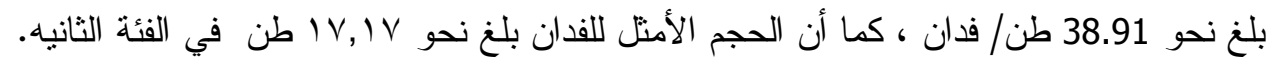

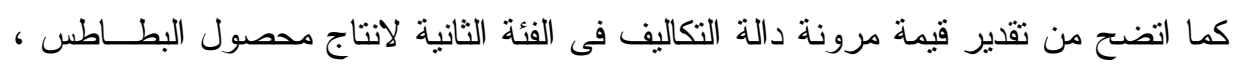
انها بلغت نحو 9 7, . ، أى أن زر اع البطاطس فى هذه الفئة بعملون فى المرحلة الاقتصادية الثانيــة

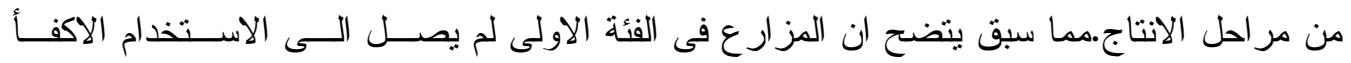

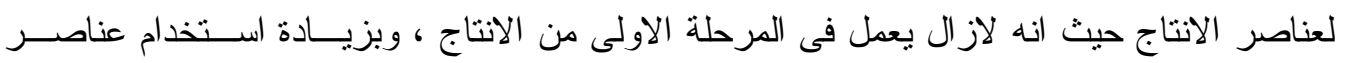

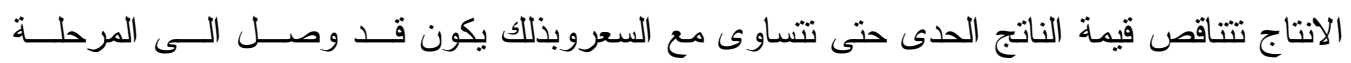

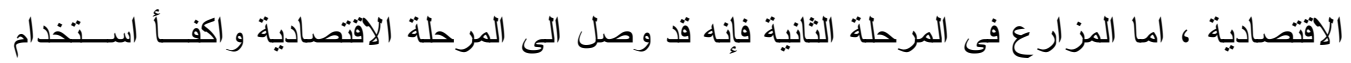
· لعناصر الانتاج 
ملحق رقم (1) : تقدير الكفاعة الإقتصادية لمدخلات دالة إنتاج البطاطس وفقاً لفئات العينة الميدانية بمحافظة الغربية عام ؛ ا ب r

\begin{tabular}{|c|c|c|c|c|c|c|c|c|c|c|}
\hline الإقتصادية * الكفاءة & العنصر & 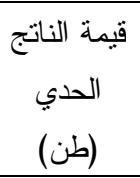 & $\begin{array}{l}\text { الحدي } \\
\text { (طن) } \\
\end{array}$ & $\begin{array}{c}\text { الناتج } \\
\text { المن } \\
\text { النون }\end{array}$ & العنصر & الوسندي & 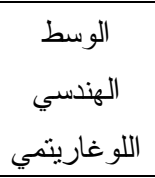 & ال العنصر & $\begin{array}{c}\text { إجمالي الناتج } \\
\text { بالدالة } \\
\text { (̂) }\end{array}$ & الفئة \\
\hline$*$ & 9,90 & 701,14 & D & l,VY & .,10r & $1 \leqslant, 7$. & $1,17 \leq \varepsilon$ & (X) ) عدد ساعات الري (ساعة) & \multirow{2}{*}{$\begin{array}{l}\mathrm{LY}=1.4010 \\
(\text { (ن Y }, 1 \wedge)\end{array}$} & \multirow{2}{*}{ 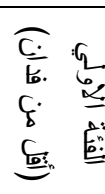 } \\
\hline$*$ & r,or & $\sum 1, \wedge \uparrow$ & $\cdot, .179$ & $\cdot, \cdot r$ & $\cdot, \wedge \varepsilon \uparrow$ & $11 \cdot r, 00$ & $r, \cdot \leq r \leq$ & كمية النقاوي (كجم) كم) (^X) & & \\
\hline * & ro, rq & 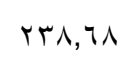 & ., & $\cdot, r$ & . & $91, r v$ & $1,97 \cdot 1$ & (رج) عمل بشري (رج) & \multirow{4}{*}{$\begin{array}{l}\mathrm{LY}=1.4518 \\
(\text { ) 28.30) }\end{array}$} & \multirow{4}{*}{ 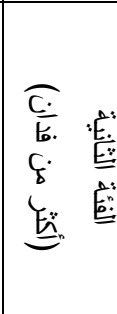 } \\
\hline$*$ & $9, r r$ & VYV, II & $\cdot, \Gamma 117$ & r,ir & $\cdot, 1 \leqslant \vee$ & rer & $1,1 r \leq \Lambda$ & |†X) عدد ساعات الري (ساعة) & & \\
\hline$*$ & $0, .7$ & $9 \wedge, \Sigma 7$ & $\cdot, \cdot \leq r r$ & $\cdot, 17$ & • Yד & $|v|, 01$ & $r, r r \leq 0$ & (و,X) كمية السماد الأزوتي (وحدة) & & \\
\hline$*$ & $\varepsilon, 9 \vee$ & 1A & $\cdot, 11 K A$ & $\cdot, \varepsilon$. & • YNA & $v, 1 \leq$ & 1,NOY & (XX) (, ) كمية السماد الفوسفاتي (وحدة) & & \\
\hline
\end{tabular}

المصدر : جمعت وحسبت من بيانات العينة الميدانية. 
1 - يوصي بزر اعة محصول البطاطس في مساحات فدان فأكثر (الفئة الثانية بالعينة) مما يؤدي إلي : بلي

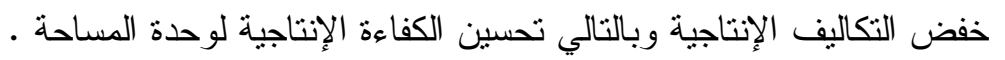
r- تحقيق الحجم المعظم للربح لانتاج محصول البطاطس من خلال الاستخدام الامتل لعنصرى

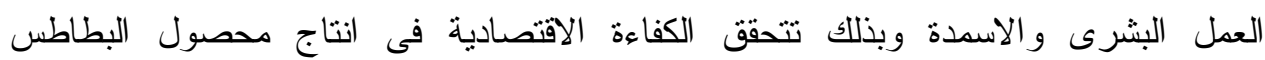

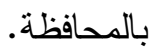

$$
\text { المر اجع ومصادر البيانات: }
$$

1 - احمد فؤاد عبد الحكيم (دكتور)، واخرون، تقدير استجابة عرض البطاطس في مصر ،المجلـــة

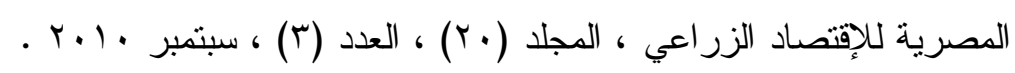

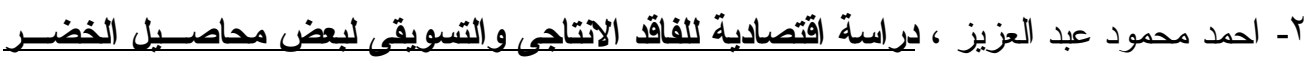

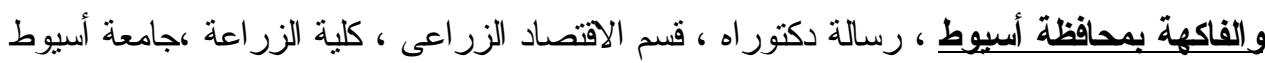

r- الجهاز المركزى للتعبئة العامة و الاحصاء ، نشرة أسعار التجزئةة ، أعداد متفرقة .

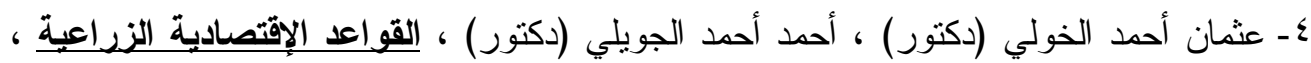

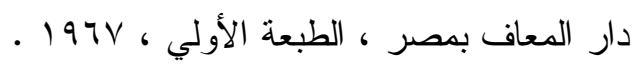

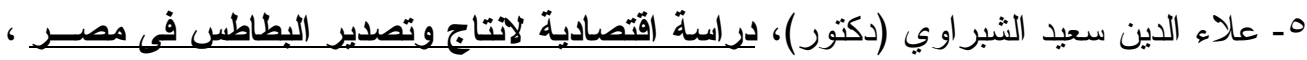

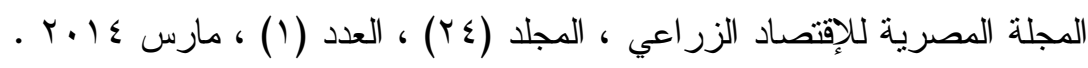
7- مديرية الزر اعة بالغربية ، سجلات إدارة الإحصاء.

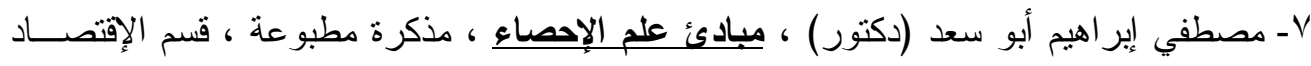

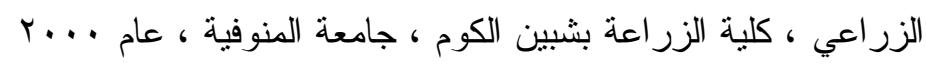

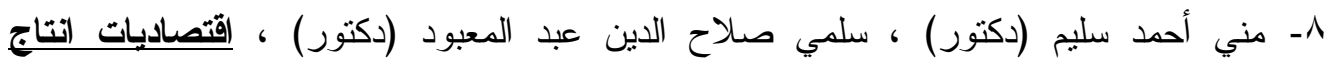

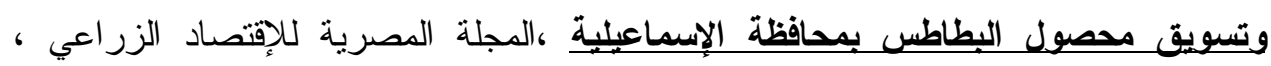

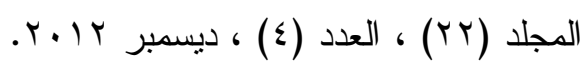

9 - و وائل عزت العبد ( دكتور ) ، واخرون ، تقدير الكفاعة الاتتاجية لاهم المحاصيل الحقلبة مـن

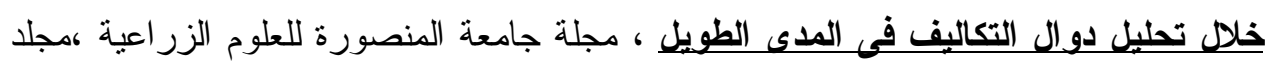

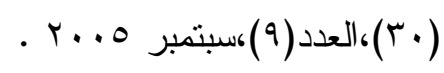

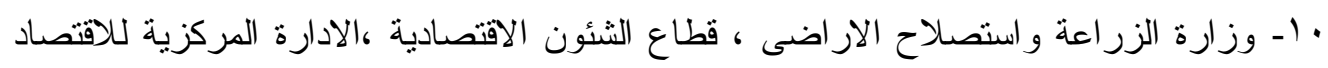

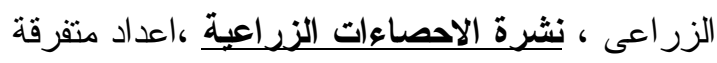

